Article

\title{
The Use of Nadir and Oblique UAV Images for Building Knowledge
}

\author{
Giuseppina Vacca ${ }^{1, *}$ (D), Andrea Dessì ${ }^{1}$ and Alessandro Sacco ${ }^{2}$ \\ 1 DICAAR, Department of Civil and Environmental Engineering and Architecture, University of Cagliari, \\ P.zza D'Armi, 09123 Cagliari, Italy; andessi@unica.it \\ 2 Studio Sacco, Via Salvator Rosa, n. 10,09100 Cagliari, Italy; alessandrosacco@hotmail.com \\ * Correspondence: vaccag@unica.it; Tel.: +39-347-820-8988
}

Received: 19 October 2017; Accepted: 26 November 2017; Published: 1 December 2017

\begin{abstract}
This paper focuses on the processing and study of 3D models obtained from images captured by an unmanned aerial vehicle (UAV). In particular, we wanted to study the accuracy gains achieved in the surveying and the measurement, such as height, area, and volume, of the dimensions of the buildings in the 3D models obtained with both nadir and oblique UAV flights. These latter types of flights are particularly suitable for the 3D modeling of cities or urban agglomerations, where it is important to achieve a complete building reconstruction, including façades and footprints of buildings. For this purpose, several UAV surveys with both nadir and oblique axes were performed. The nadir flight acquired images over an area of about 3.5 hectares containing 30 buildings, while the second flight, performed with both a nadir camera and an oblique camera, was conducted on a single building. The images from the flights were processed with Photoscan software by Agisoft and with Pix4D, studying their different potentialities and functionality. The results were compared with the data from the 1:2000 scale Geotopographic Database (DBGT), with the results of a Global Navigation Satellite System (GNSS) survey and with 3D model from the Terrestrial Laser Scanner (TLS) survey. The obtained results have shown that oblique UAV flights increase the achievable accuracy both in terms of the number of points in a point cloud, and in the in measurements taken on the 3D models, with respect to the limited cost, and at the increase in time for surveying and image processing.
\end{abstract}

Keywords: UAV; photogrammetry; planning; oblique images

\section{Introduction}

The growing interest in recent years in unmanned aerial vehicles (UAVs) by the scientific community, software developers, and geomatics professionals, has led these systems to be used more and more widely, in different fields of engineering and architecture [1]. This is thanks, above all, to their flexibility of use and low cost compared to traditional photogrammetric flights using expensive metric digital cameras or LiDAR sensors [2]. UAV systems were used first for military purposes [3] and later for civilian ones [4], such as agricultural and forest management (precision farming, assessment of woodlots, fire surveillance, etc.) [5,6], archaeology and cultural heritage surveying (3D documentation and mapping) $[7,8]$, for environmental surveying (land and water monitoring) [9,10], for traffic monitoring (surveillance, travel time estimation, etc.) [11], and for 3D reconstruction [12]. Specifically, in recent years, UAVs have also been used in the field of monitoring and inspection of public buildings, or buildings that are remarkable in terms of size and architecture. This is mainly due to the focus on sustainability and resource efficiency in the building and infrastructure sector, which aims to extend their lifetimes. This type of monitoring and inspection has always required sophisticated and expensive methods to quickly and safely identify possible damage that could jeopardize the stability and safety of buildings and people. Through the use of remote checking using UAVs, the monitoring 
and inspection of buildings can be brought to a new level of quality and saving. There are several papers in the literature that relate to the use of UAVs [13-15] in this field, and several algorithms that have been implemented were developed for the automatic extraction of deformations or damage. Works that have investigated the use of UAVs, using both nadir and oblique images, have studied contributions in terms of accuracy and advantages in the study of buildings with such systems [16]. This work takes part in this research effort by exploring, in further depth, the contributions that UAV systems can provide to professionals in the study of existing buildings, in terms of dimensional knowledge, territorial planning, and the state of health of a building, for the purpose of maintenance and restoration.

This growing development is due, as said above, to the availability on the market of low-cost UAV systems equipped with nonprofessional or SLR (single lens reflex) cameras and GNSS/INS system (global navigation satellite system/inertial navigation system) for positioning the UAV system and its sensors [4]. The GNSS positioning system is mostly used in stand-alone mode and, together with the INS, assists and guides the UAV during flight.

In general, a UAV system survey requires flight planning, a ground control points (GCPs) survey in the reference system where the flight has to be georeferenced, image acquisition, calibration of the camera and, finally, image processing for the 3D models and photogrammetric product extraction. The photogrammetric products that can be obtained from image processing are DTM (digital terrain model) or DSM (digital surface model), orthophotos, and other graphical outputs.

UAV surveys are usually nadir, which means that the images are shot with the camera axis along the vertical direction; they provide both a forward overlap between shots and a side one between strips, allowing for the reconstruction of the surveyed territory or object in 3D. This type of survey is not appropriate for 3D modeling of towns or cities, where it is important to have a complete 3D modeling of each building, including the façades and footprints of buildings. In such cases, in order to improve the 3D model, the data from the nadir UAV survey can be completed with point clouds from a terrestrial laser scanner (TLS) or from a traditional land survey; this produces a 3D model which is both complete and more accurate $[17,18]$. Of course, this integration requires longer times and higher costs for staff and equipment. In order to offset this, since 2008-2009, there have been experimentations in integrating nadir UAV images with oblique ones, that is, shot with the camera axis at an angle with respect to the vertical. The results up to date seem to show an effective improvement in the 3D city model reconstruction with a better inclusion of façades and footprints of the buildings [19]. However, it is mostly with the integration of computer vision algorithms in the software tools used for processing the UAV surveys that the use of oblique shots is becoming a standard technique [20]. As a matter of fact, in a 3D city model reconstruction, the dense point clouds produced by the oblique shots allow for entirely reconstructing the façades and footprints of the buildings, improving the representation of the DSM from the single nadir viewpoint to a more complete model that can be used to perform better and deeper kinds of analysis on the building, e.g., on the health status of the façades or structural elements [19].

The research presented in this paper concerns a study of the potential of the use of images from both nadir and oblique UAV surveys for the measurement of the dimension of the buildings, such as heights, areas, and volumes, in order to set the parameters related to the production of urban and suburban planning. The knowledge of the area and volume of each building, in fact, has significant importance for urban planning and, yet, often there are no maps that are both up-to-date and at the right scale to determine them. In such cases, UAV systems can help with respect to both acquisition and processing times and of costs. In particular, this would be useful, for example, in updating digital mapping and/or DBGT (Geotopographic Database) at the small or medium scale [20]. The study also concerned the contribution that oblique images can give to the dimensional knowledge about the building and the 3D reconstruction of façades and footprints of buildings.

For this purpose, several UAV flights performed with nadir and oblique cameras have been examined. The first case study was a nadir flight covering an area of about 3.5 hectares, containing 
30 buildings; the second was performed with both nadir and oblique cameras, and involved a single building. In the first case study, we studied the accuracy of a nadir flight for determining the volumetric parameters of a built area. The results were compared with information from the 1:2000 scale DBGT $2 \mathrm{k}[21]$ and with the results of a GNSS survey.

In the second case study, we concentrated on a single building in order to ascertain the increase in accuracy due to using an integrated nadir/oblique survey with respect to a purely nadir one. In this case, the results were compared with those obtained from a Terrestrial Laser Scanner (TLS) survey.

The images from the flights were processed with two different software packages: Photoscan by Agisoft (St. Peterburg, Russia) [22] and Pix4D (Lausanne, Switzerland) [23].

\section{Methodology}

The purpose of this research is to study the potentialities and accuracy of 3D models obtained from imagery acquired by UAV systems in order to obtain measurements of buildings (height, area, and volume) for urban planning purposes. Additionally, the aim is to evaluate the improvement of the 3D model of buildings and their quantitative and qualitative knowledge by integrating the only nadir flight with an oblique flight, i.e., executed with the axis positioned with a tilt of about $45^{\circ}$ from the nadir position.

In order to achieve these goals, we performed two UAV flights, one nadir (Case Study 1) that was covering an area of about 3.5 ha containing 30 buildings, and another (Case Study 2) integrated nadir and oblique flight on a single building. The FlyNovex UAV system by FlyTop S.p.A. (Figure 1), a hexacopter weighing $6 \mathrm{~kg}$ with a $5 \mathrm{~km}$ range and 20 min autonomy, was used for both case studies. The system contains an IMU (inertial measurement unit), a GPS receiver, and a camera mounted on the gimbal. The UAV has a wireless connection with a computer working as the ground control station. The camera is a Sony Alfa 6000 with a resolution of $6000 \times 4000$ pixel, a focal length of $16 \mathrm{~mm}$, sensor size of $23.5 \mathrm{~mm} \times 15.6 \mathrm{~mm}$, and a pixel size of $3.92 \mu \mathrm{m}$. The camera's calibration parameters are reported in Table 1.

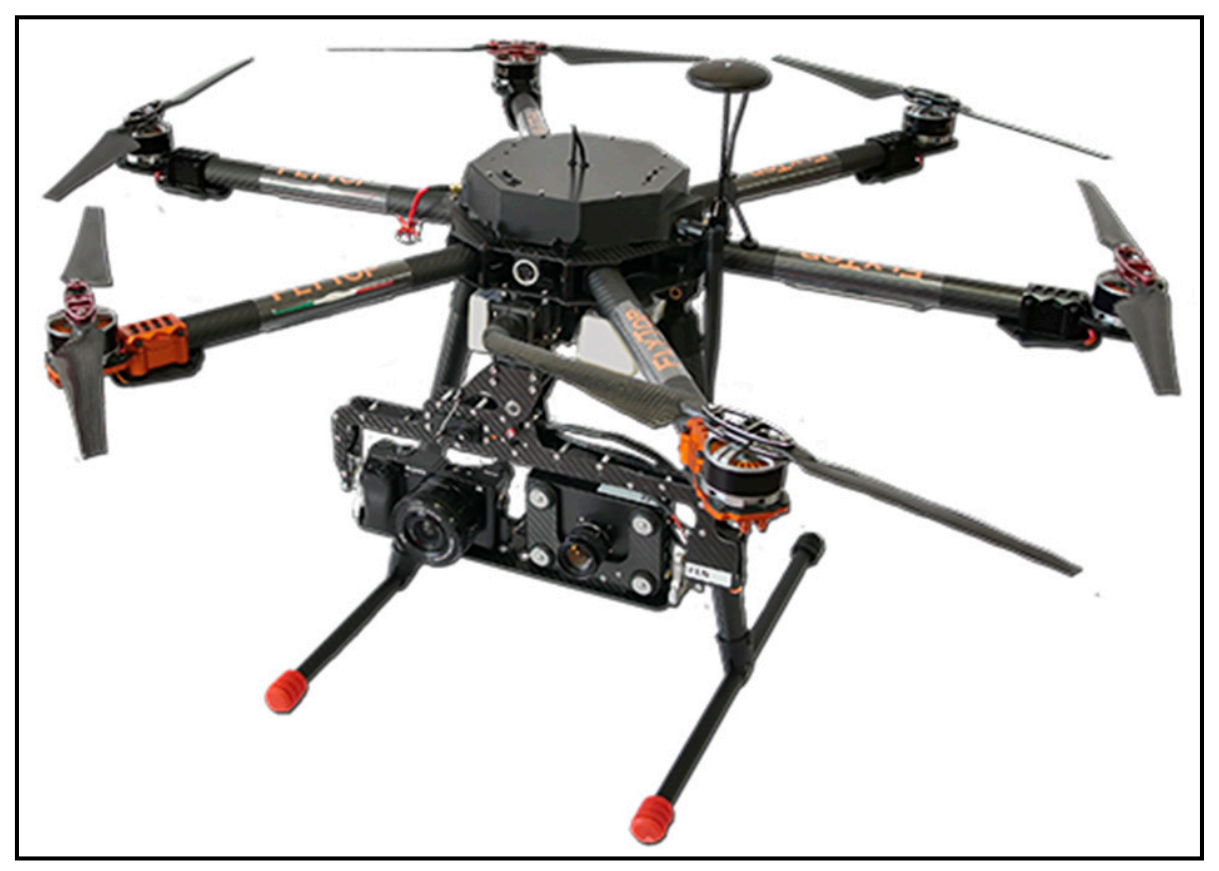

Figure 1. FlyNovex UAV (unmanned aerial vehicle) system. 
Table 1. Calibration parameters of the camera.

\begin{tabular}{cc}
\hline Parameters & Data \\
\hline Focal lengh & $16 \mathrm{~mm}$ \\
Pixel size $x$ & $0.004 \mathrm{~mm}$ \\
Pixel size y & $0.004 \mathrm{~mm}$ \\
fx & 4074.9533 pixel \\
fy & 4074.4493 pixel \\
cx & 2996.9340 \\
cy & 1936.5894 \\
skew & 0.934748 \\
k1 & -0.019653 \\
K2 & 0.013821 \\
K3 & -0.006089 \\
K4 & 0.008760 \\
p1 & -0.001868 \\
p2 & -0.001065 \\
Date & 14 October 2016 \\
\hline
\end{tabular}

The images were georeferenced using the ground control points (GCPs) signalized with wooden circular targets with a diameter of $24 \mathrm{~cm}$ (Figure 2). The shape and size of the targets on images acquired from a height of about $100 \mathrm{~m}$. The points were surveyed using a GNSS receiver in RTK mode with the ITALPOS Permanent Stations Network [24] determining their coordinates in the ETRF2000 datum [25]. The r.m.s. of the GNSS point is about 0.05-0.10 $\mathrm{m}$ [26].

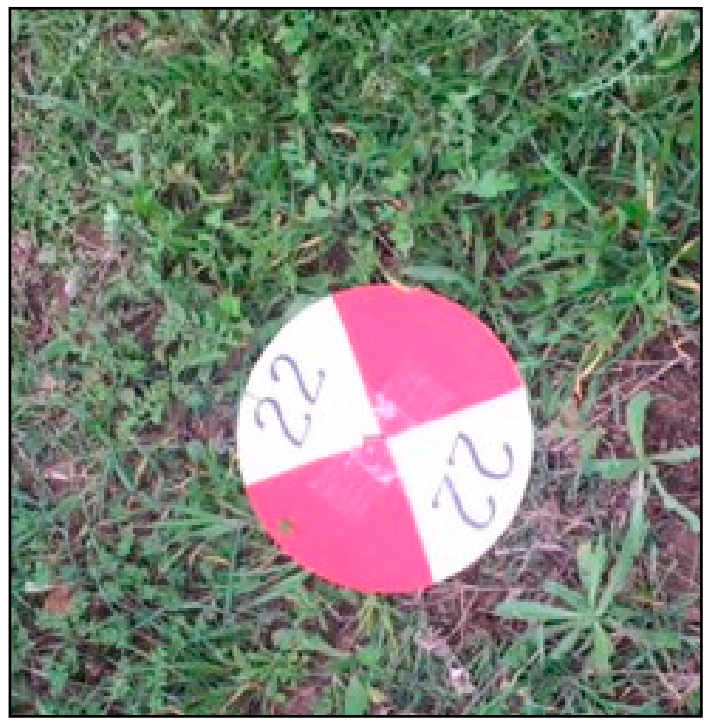

Figure 2. Target.

The images were processed using Photoscan and Pix4D. Both packages implement the Structure from Motion (SfM) algorithm. The SfM is a low-cost photogrammetric method for high-resolution topographic reconstructions. The SfM operates under the same basic tenets of the stereoscopic photogrammetry, namely that the 3D structure can be resolved from a series of overlapping images. However, they fundamentally differ because in SfM, the geometry of the scene, camera positions, and orientation is solved automatically without points known. The points are solved simultaneously using a highly redundant, iterative bundle adjustment procedure, based on a database of features automatically extracted from a set of multiple images with a high degree of overlap. The approach is most suited to sets of images with a high degree of overlap that capture the full three-dimensional 
structure of the scene viewed from a wide array of positions, or as the name suggests, images derived from a moving sensor $[27,28]$.

The Photoscan and Pix4D workflows consist in the following main steps: data import, image alignment, generation of the sparse cloud, optimization of image alignment, and dense image matching.

For image processing, Photoscan and Pix4D software proposes to the user, for each processing phase, various parameters determining the accuracy and processing time of the final product. The following is a brief description of the parameters used exclusively for the generation of sparse and dense clouds, while the parameters used for mesh and orthophoto generation will be omitted because, although being calculated, they have not been analyzed in this research. In order to generate the sparse point cloud, Photoscan requires an accuracy parameter that can be set to highest, high, medium, low, or lowest. With the high accuracy setting the software works with the photos at their original size, the medium setting causes image downscaling by factor of 4 , at low accuracy source files are downscaled by factor of 16, and the lowest value means further downscaling by 4 times more. The highest accuracy setting upscales the image by factor of 4 . In order to generate the dense cloud, the quality and depth filter parameters must be chosen. Quality specifies the desired reconstruction quality. Higher quality settings can be used to obtain more detailed and accurate geometry, but they require longer processing times. Interpretation of the quality parameters here is similar to that of accuracy settings given in spare cloud generation. The depth filter may be set to mild, aggressive, or moderate, depending on the type the object and the details that must be visible in the 3D model [29].

Regarding Pix4D, the parameters involved are: for the initial processing, the keypoint image scale, corresponding to accuracy in Photoscan; for the dense cloud, the image scale (again corresponding to accuracy) and the point density, which may be set to optimal, high, and low, define the density of the densified point cloud. Finally, the minimum number of matches represents the minimum number of valid re-projections of this 3D point to the images, and may be set to 3, 2, 4, 5, and 6 [30].

The accuracy of the 3D model, the number of cloud points, and the processing time of the images vary in function of these parameters. For each case study, finding the right compromise to obtain point clouds with accuracies that were compatible with the search objectives, and a processing time that is not excessively long, has been attempted. Within the two case studies, the parameters used will be reported.

In Case Study 1, the area and volume measurements from point clouds are compared with those extracted from the Geo-Topographic Database (DBGT) 2k, completed in 2008. This was the only cartographic source we could use for comparing areas and volumes since, for privacy reasons, we could not perform direct measurements on the buildings with a total station or TLS. For each single measurement A (area or volume) obtained from the DBGT 2k, we determined the root mean square (r.m.s.) through the law of propagation of the variance, knowing the r.m.s. of quantities, of which the indirect measurement is a function (Equation (1)). These quantities are considered to not be correlated, thus the law of propagation is reduced to:

$$
A=F(x, y, z) ; \sigma_{A}^{2}=\left[\left(\frac{\partial F}{\partial x}\right)^{2} \cdot \sigma_{x}^{2}\right]+\left[\left(\frac{\partial F}{\partial y}\right)^{2} \cdot \sigma_{y}^{2}\right]+\left[\left(\frac{\partial F}{\partial z}\right)^{2} \cdot \sigma^{2} z\right]
$$

In Equation (1), the quantities $x, y$, and $z$ represent the lengths and height forming the area and the volume of the building. The values of their r.m.s are assumed to be equal to the tolerances specified in the technical specification of the DBGT [31], that is:

- For the distances: $\sigma_{\mathrm{L}}=(0.5+\mathrm{L} / 2000) \mathrm{m}$, for $\mathrm{L} \leq 600 \mathrm{~m}$; and $0.80 \mathrm{~m}$ for $\mathrm{L}>600 \mathrm{~m}$; and

- For the heights (including building heights): $\sigma_{\mathrm{Q}}=0.50 \mathrm{~m}$.

The areas and volumes obtained from the 3D models were compared with the corresponding measure on the DBGT, verifying that the difference between this was smaller than the r.m.s. of the DGBT measure, as calculated with Equation (1). 
The comparison of the distances was accomplished by comparing the distances measured on the 3D model with those surveyed on site with GNSS RTK. The GNSS survey was referenced in ETRF2000 datum using the ITALPOS Permanent Stations Network. The r.m.s. of the distance is about $0.07-0.10 \mathrm{~m}[26]$.

For Case Study 2, the 3D model of the single building obtained from the combined nadir/oblique flight was validated by comparison with the data obtained from a survey using a TLS. The instrument used was a Faro Focus 3D [32]. This is a compact scanner characterized by an operative range that varies between $0.6 \mathrm{~m}$ and $120 \mathrm{~m}$, with a linear distance error of $\pm 2 \mathrm{~mm}$ for scanner-object distances comprised between $10 \mathrm{~m}$ and $25 \mathrm{~m}$. It has a vertical visual field of $305^{\circ}$ and a horizontal one of $360^{\circ}$. The vertical and horizontal resolution is $0.009^{\circ}$.

The processing of the scans was done using the JRC Reconstructor Software v. 3.1.0 (335) [33] by Gexcel Ltd. (Spin Off of the University of Brescia, Bergamo, Italy). Reconstructor is a software that enables all the processing operations of the point cloud before the 3D model of the structure or building scanned is obtained.

The comparison was done both comparing the measurements of distances, areas, and volumes taken on the point clouds obtained from UAV and TLS surveys, and comparing the point clouds themselves using the CloudCompare software (Open Source Software) [34]. Specifically, the comparison was done by calculating the minimal distance between every point of the models using the nearest neighbor algorithm. Furthermore, the software allows the calculation of statistical values, such as the minimal distance, maximal distance, average distance, and standard deviation.

Figure 3 shows the workflow followed in the two case studies both for the processing of the images and the generation of the point clouds, and for the comparison between the resulting point clouds and the data from the DBGT (Case Study 1), and the point clouds from the TLS survey (Case Study 2).

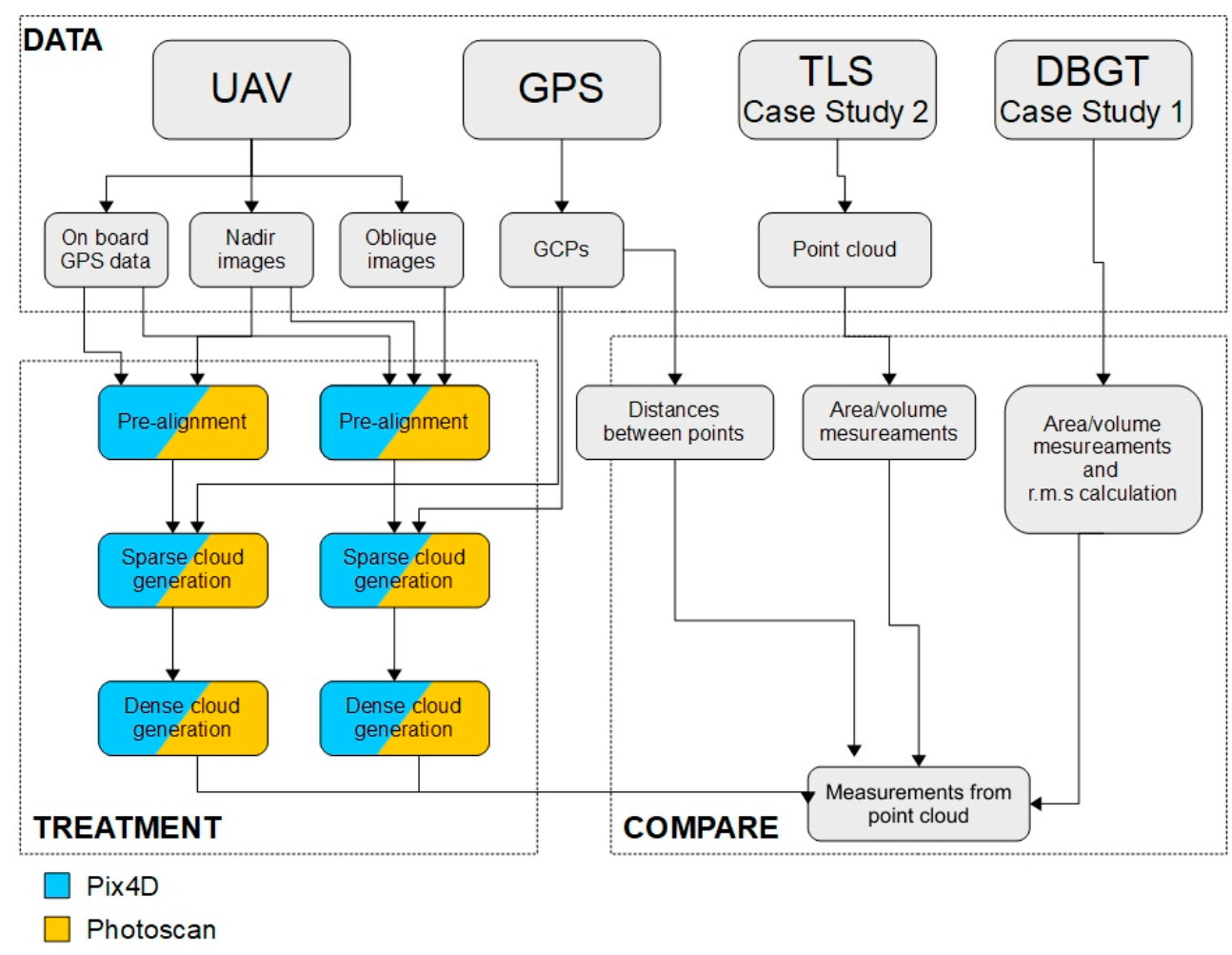

Figure 3. Workflows for 3D point cloud generation and their comparison with Terrestrial Laser Scanner (TLS) and DGBT. 


\section{Case Studies}

The following paragraphs present two case studies. In particular, important data such as the flight plan, the results of the image processing, the measurements taken, and their comparison have been in this part illustrated.

\subsection{Case Study 1-Nadir Survey Flight}

For the first case study, we chose an area within a sparsely built territory, but outside any urban center and without significant infrastructures. The extent of the area is about 3.5 ha and it contains 30 buildings (Figure 4). Table 2 shows the parameters chosen for the flight plan.

The UAV system used is the FlyNovex hexacopter by FlyTop S.p.A., already described in the previous paragraph. Figure 5 shows the flight path of the UAV.

Table 2. Parameters of the flight plan.

\begin{tabular}{cc}
\hline Flight's Parameters & Data \\
\hline Area Covered by the Images & $5.6672 \mathrm{ha}$ \\
Flight height & $90 \mathrm{~m}$ \\
GSD & $2.20 \mathrm{~cm}$ \\
Forward overlap & $80 \%$ \\
Side overlap & $73 \%$ \\
Number of strips & 7 \\
Number of images & 110 \\
\hline
\end{tabular}

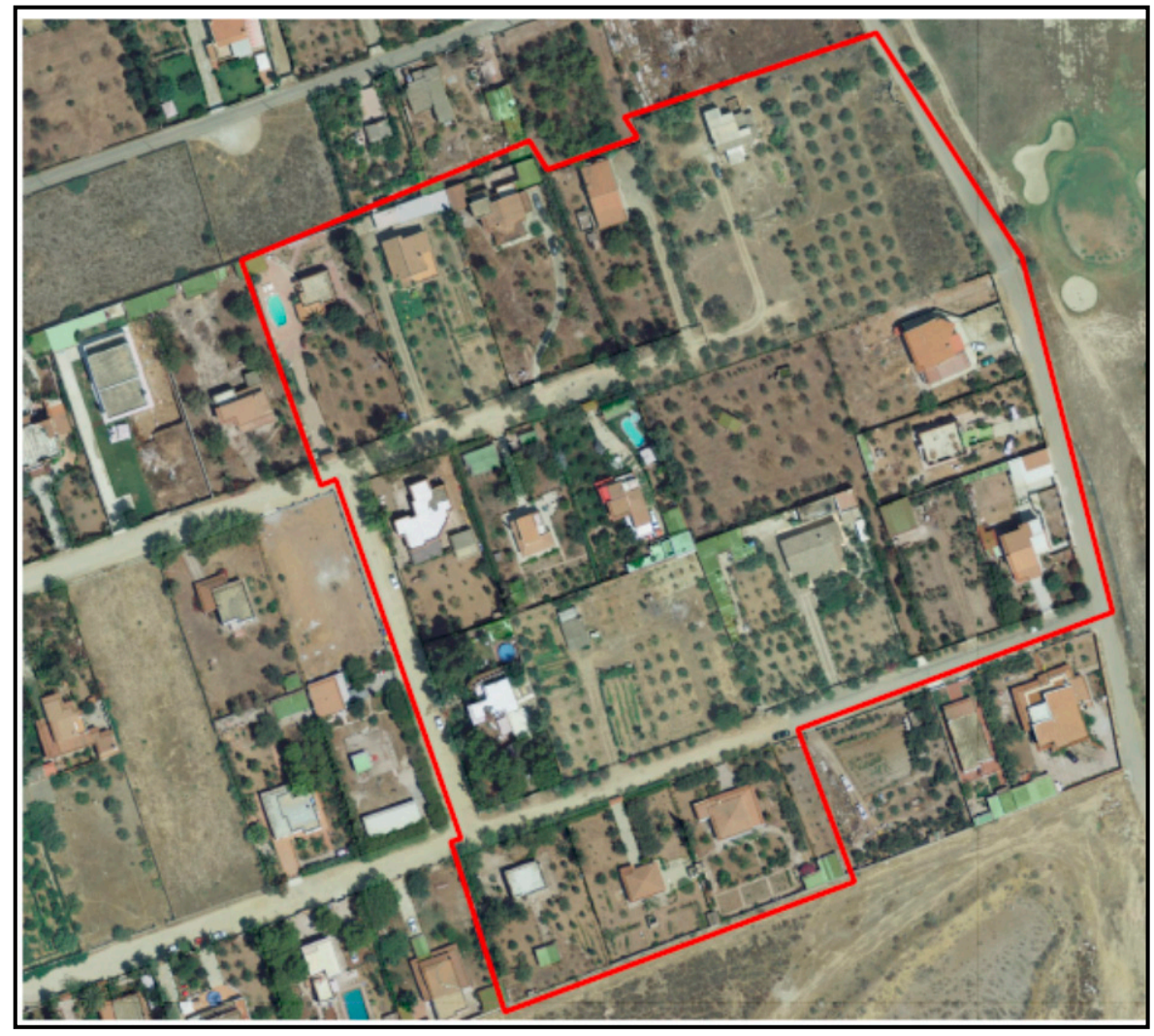

Figure 4. Area surveyed. 


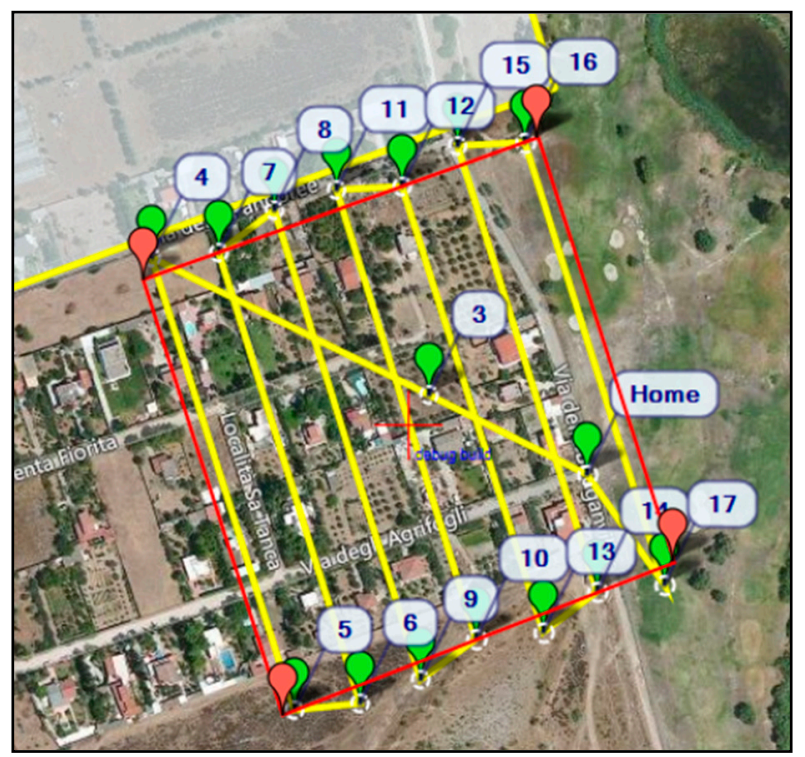

Figure 5. Flight path. The numbers indicate the waypoints of the strips.

In order to georeference the point clouds, we used five GCPs positioned on the roads of the surveyed areas. This choice was dictated by the impossibility of placing GCPs at different heights, such as on the roofs of buildings, as suggested by scientific literature, for reasons of privacy, since the buildings are privately owned. The good distribution of GCPs is of high importance not only for the image orientation, but also for the prevention of block deformation effects that may result from the remaining systematic errors in the camera calibration $[35,36]$. The coordinates of the points were determined using a GNSS RTK survey in the ETRF2000 datum.

The flight was performed 13 November 2016 at 14:00. The time from take-off to landing was about 8 min and $30 \mathrm{~s}$.

\subsubsection{Image Processing}

\section{Agisoft Photoscan Processing}

The 3D model was georeferenced in the ETRF2000 datum using four of the five GCPs; the fifth was used as a check point. The errors of the georeferencing process are reported in Table 3.

Table 3. Photoscan Georeferencing errors.

\begin{tabular}{cccc}
\hline GCP & E Error $(\mathbf{m})$ & N Error $(\mathbf{m})$ & H Error $(\mathbf{m})$ \\
\hline 99 & -0.0167 & -0.0005 & -0.0140 \\
26 & -0.0035 & -0.0064 & 0.0202 \\
21 & 0.0082 & 0.0149 & 0.0102 \\
19 & 0.0125 & -0.0078 & -0.0166 \\
Mean (m) & 0.0001 & 0.0001 & -0.0001 \\
r.m.s. $(\mathrm{m})$ & 0.0131 & 0.0104 & 0.0181 \\
\hline
\end{tabular}

Looking at Table 3, we can point out that the error values on the GCPs are all below $2 \mathrm{~cm}$ and this is compatible with the accuracy of the instrument used. The coordinate difference on the check point is $0.014 \mathrm{~m}$ in $\mathrm{E}, 0.097 \mathrm{~m}$ in $\mathrm{N}$, and $-0.021 \mathrm{~m}$ in $\mathrm{H}$. We must point out that a single check point is not enough to determine the quality of a 3D model and that scientific literature suggests using many more. For this reason, in our work, the accuracy of the 3D models was assessed by comparing them with the data obtained from surveys having a greater accuracy (e.g., GNSS or TLS surveys) or from the DGBT. 
The dense point cloud $(22,112,405$ points) was calculated setting the quality parameter to "medium" and the depth filtering to "moderate". The choice of these parameters, medium quality in particular, was dictated by the results achieved on the check point and by the need for a compromise between a reasonable processing time and an accuracy level compatible with the 1:2000 scale of the survey [35].

The processing of the images continued with the generation of 3D meshed, raster DSMs, and orthophotos, although these products were not used in our research.

The mesh (Figure 6) was built with the "Arbitrary" algorithm, generating a solid 3D model with $4,422,480$ faces. Finally, we produced the raster DSM, with a resolution of $6424 \times 6292$ pixels and a GSD (ground simple distance) of $8.34 \mathrm{~cm}$ (Figure 7), and the orthophoto (Figure 8), with a resolution of 18,004 $\times 21,064$ pixels and a GSD of $2.09 \mathrm{~cm}$.

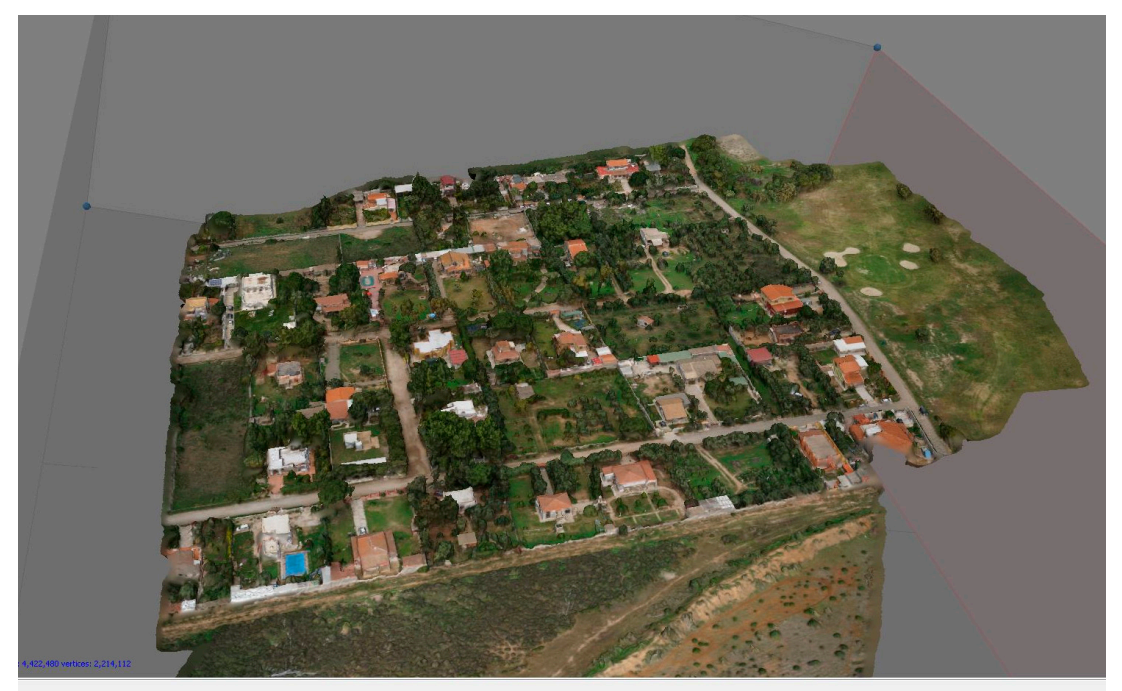

Figure 6. Photoscan mesh.

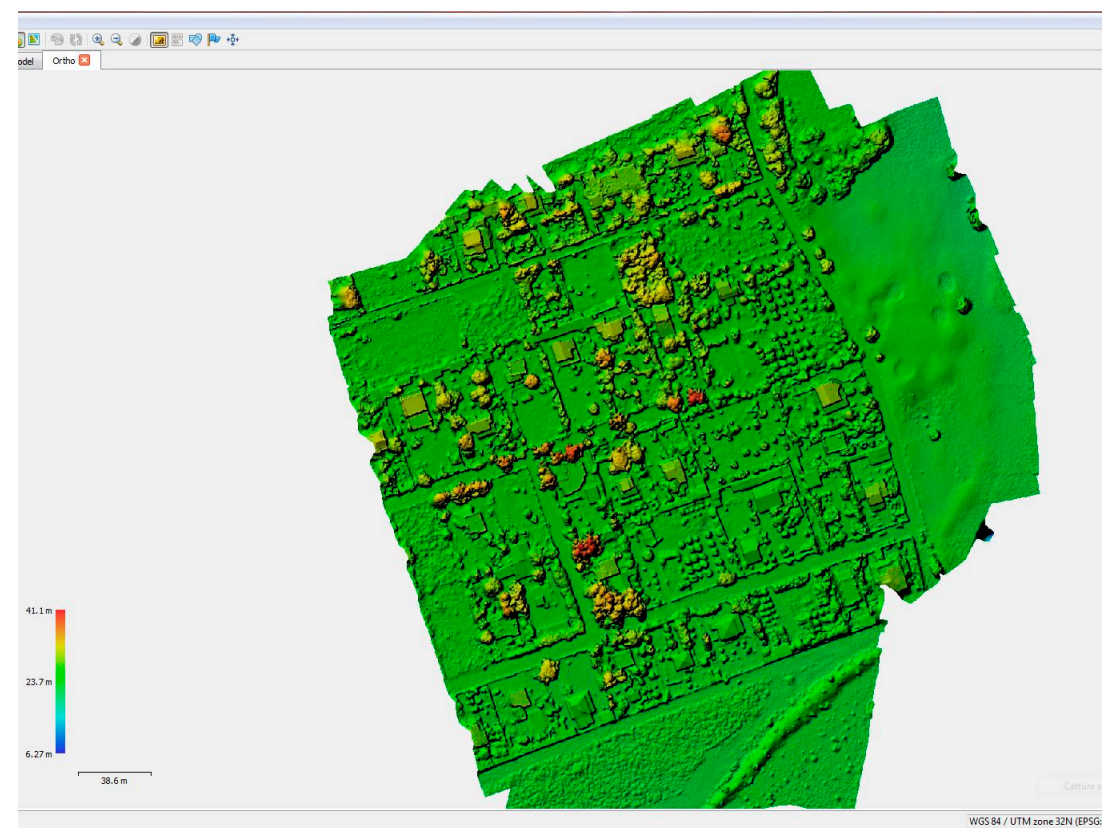

Figure 7. Photoscan raster DSM. 


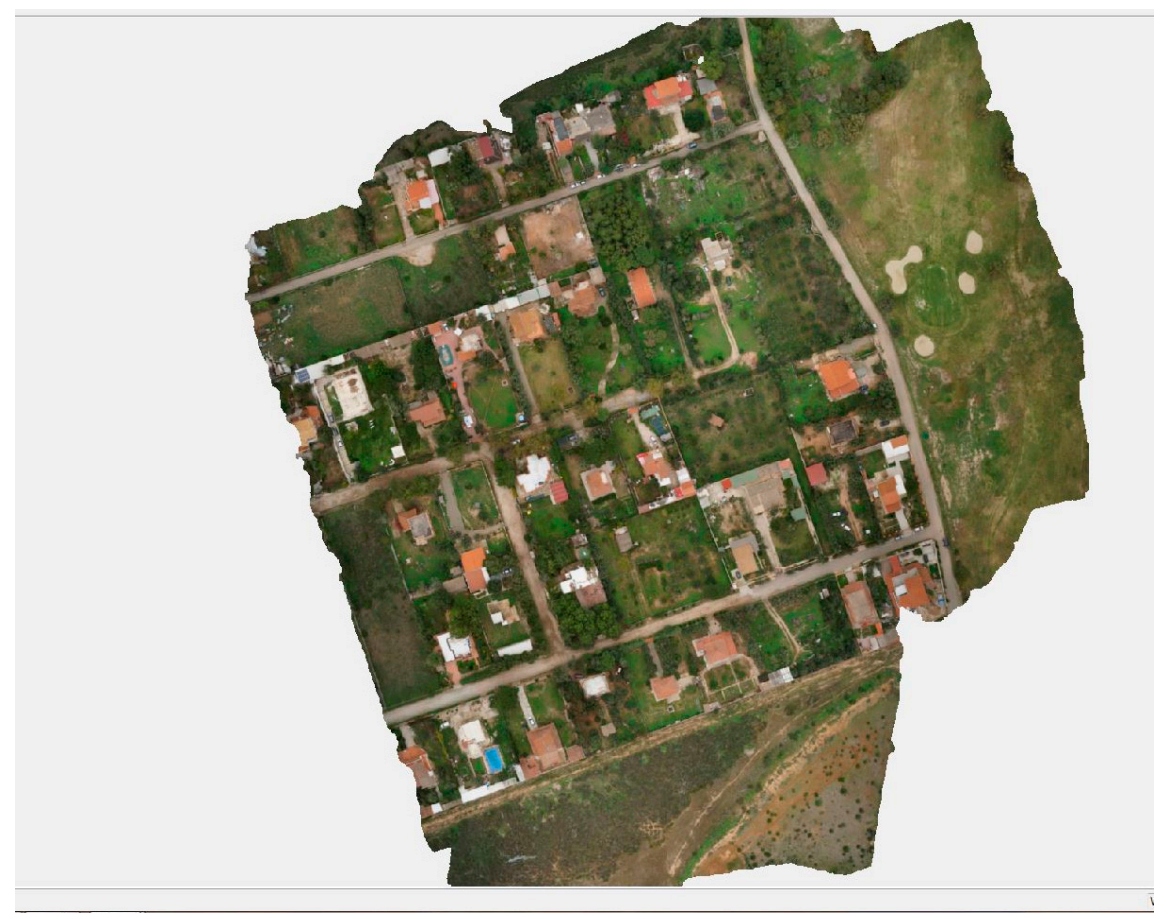

Figure 8. Photoscan orthophoto.

\section{Pix4D Processing}

The Pix4D software package was also used to obtain a 3D model and the corresponding orthophotos. Additionally, in this case, the model was georeferenced in ETRF2000 using four of the GCPs and leaving one fifth as a check point. The georeferencing errors are shown in Table 4.

Table 4. Pix4D georeferencing errors.

\begin{tabular}{cccc}
\hline GCP & E Error $(\mathbf{m})$ & N Error $(\mathbf{m})$ & Z Error $(\mathbf{m})$ \\
\hline 99 & 0.013 & 0.004 & 0 \\
26 & -0.001 & -0.007 & 0 \\
21 & -0.013 & -0.015 & -0.003 \\
19 & 0.002 & 0.018 & -0.001 \\
Mean (m) & 0.000 & 0.000 & -0.001 \\
r.m.s. (m) & 0.009 & 0.012 & 0.001 \\
\hline
\end{tabular}

In Table 4, we can note that the GCP errors are, again, below $2 \mathrm{~cm}$ and this is compatible with the accuracy of the instrument used. The coordinate differences on the check point, on the other hand, are $0.011 \mathrm{~m}$ in $\mathrm{E},-0.014 \mathrm{~m}$ in $\mathrm{N}$, and $-0.037 \mathrm{~m}$ in $\mathrm{H}$.

Firstly, the images were orientated calibrating the camera parameters and producing a sparse point cloud, using the following parameters: Initial Processing.

Key point image scale: Full.

Then, the dense point cloud was generated setting the following parameters:

- Image scale: $1 / 2$

- Point Density: Optimal

- Minimum Number of matches: 3

With these parameters, the software produced a dense point cloud containing 18,437,348 points. For generating the mesh, the following parameters were used: 
- $\quad$ Octree: 12

- Texture size: $8192 \times 8192$ pixels

- Decimation criteria: Sensitive

These parameters produced a mesh of 1,000,000 triangles (Figure 9). The raster DSM (Figure 10) and the orthophoto (Figure 11) were generated with a GSD value of $2.15 \mathrm{~cm}$.

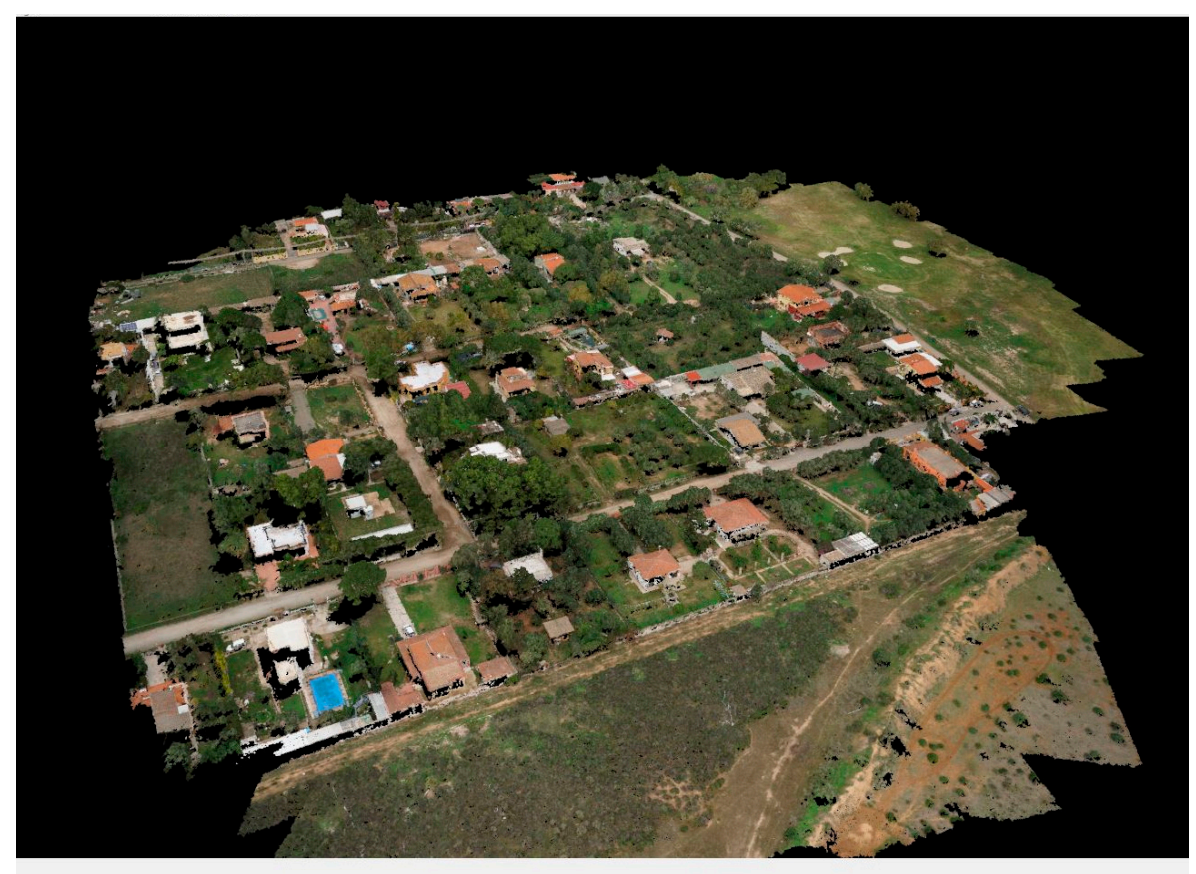

Figure 9. Pix4D mesh.

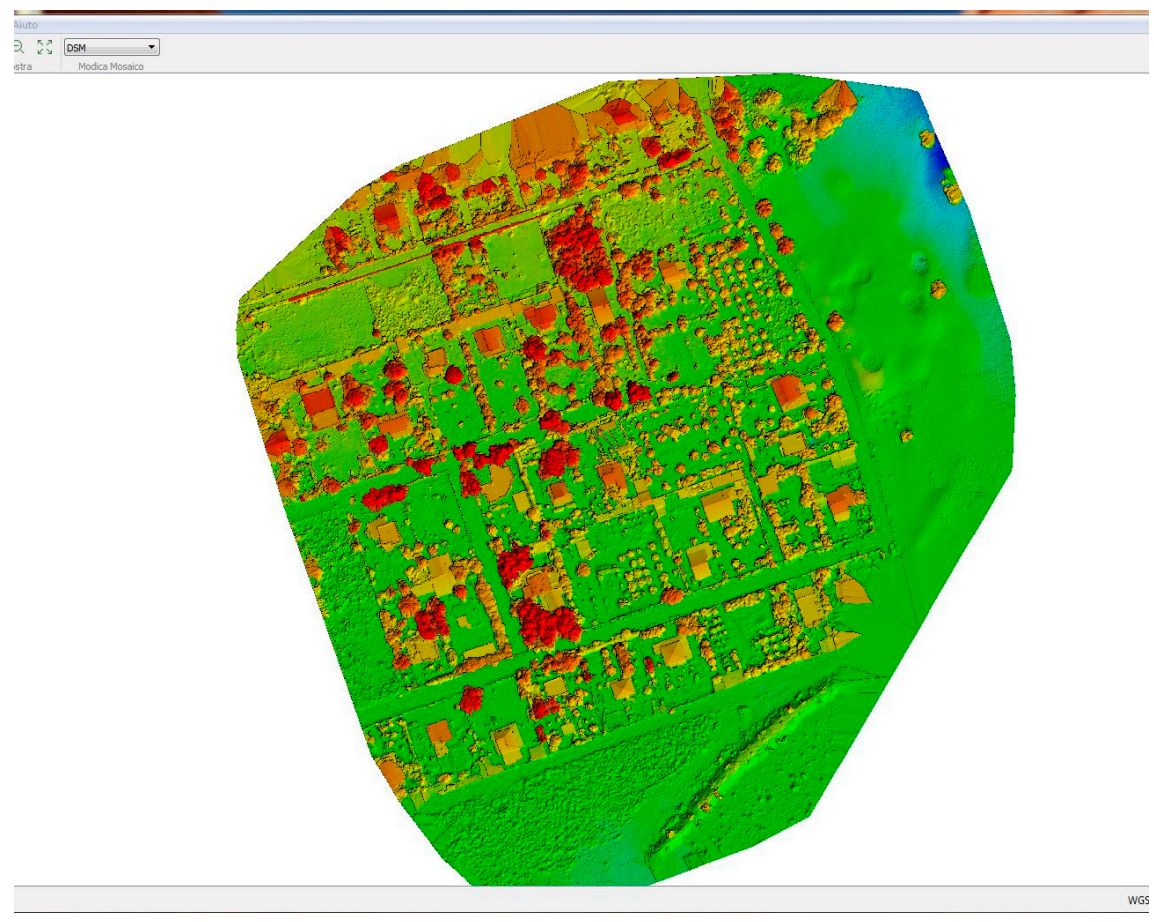

Figure 10. Pix4D raster DSM. 


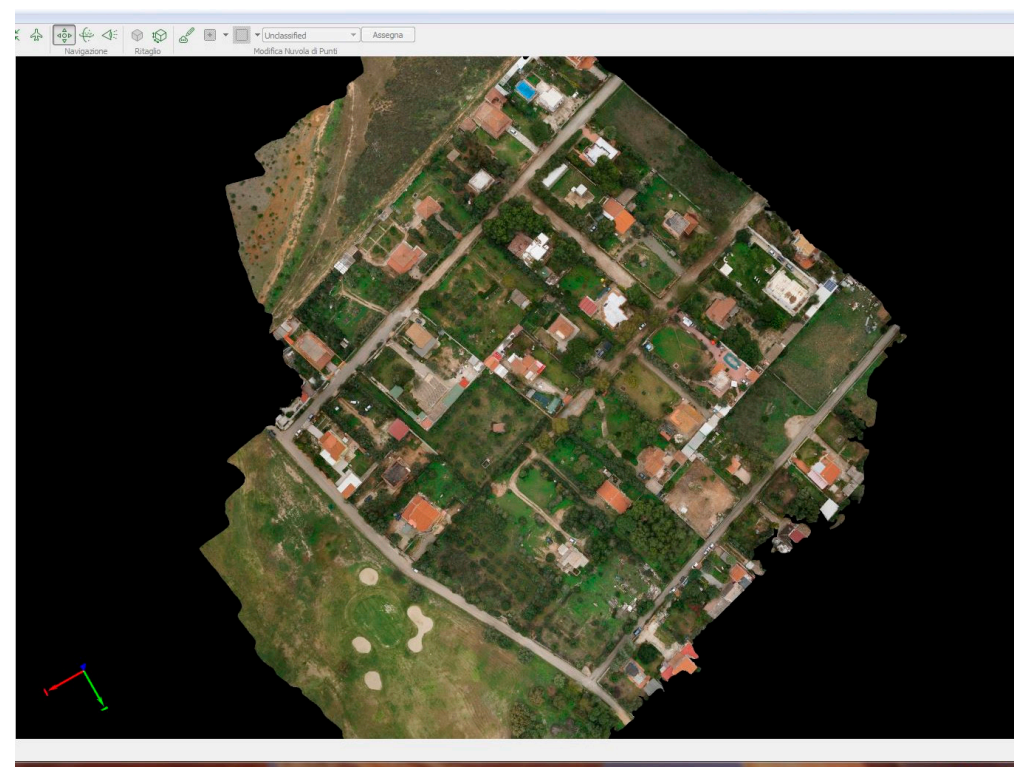

Figure 11. Pix4D orthophoto.

\subsubsection{Results of Case Study 1}

Measurements of distances, areas, and volumes were performed on 3D models obtained from Photoscan and Pix4D. In detail, the measurements taken were:

- Ten distances obtained between the GCPs (Figure 12); point coordinates were determined by GNSS RTK survey; in Table 5, DGCP is the surveyed distance, DPS is the distance measured on the Photoscan model, and DP4D is the distance measured on the Pix4D model.

- Thirty areas of the 30 buildings (Figure 13) inside the surveyed area; in Table 6, ADBGT is the area extracted from the DBGT, APS is the area measured in Photoscan, and AP4D is the area measured in Pix4D.

- Thirty volumes of the 30 buildings inside the surveyed area (Figure 13); in Table 7, VDBGT is reported the volume extracted from the DBGT, VPS is the volume measured in Photoscan, and VP4D the one measured in Pix4D.

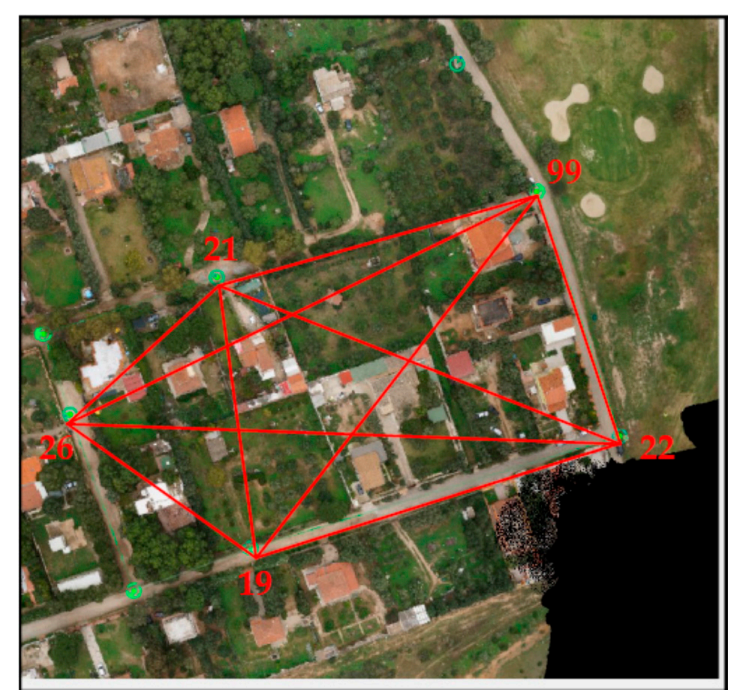

Figure 12. Distance measurements. 
In detail, Table 5 reports the results of the comparison between the measured distances. The analysis in this table shows that some of the measured distances fall outside of the tolerance on the GCP distances (about 7-10 cm), but they are well within the tolerances for large-scale cartography. Even when comparing the distances obtained from Photoscan and those from Pix $4 \mathrm{D}$, the values of the differences are satisfactory, with an r.m.s. of $5 \mathrm{~cm}$ and a mean of $2 \mathrm{~cm}$.

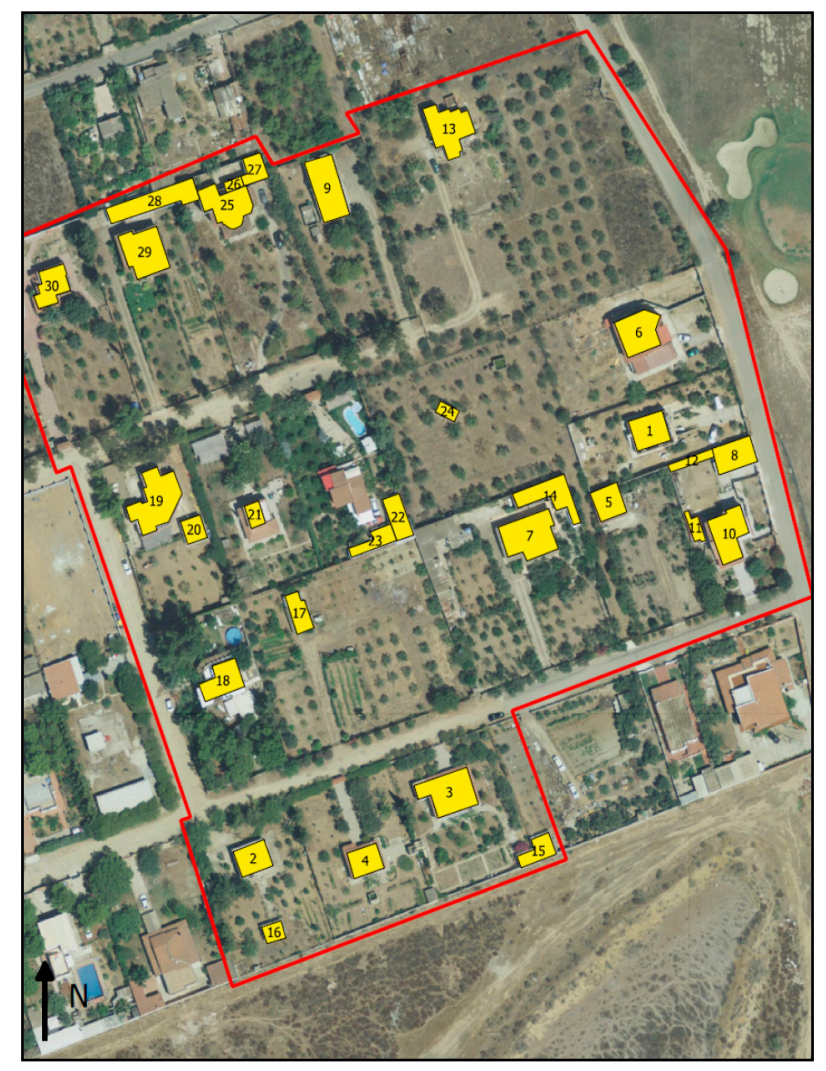

Figure 13. The buildings whose areas and volumes were measured.

Table 5. Results of the distance measurements.

\begin{tabular}{ccccc}
\hline Distances & DGCP (m) & DPS-DGCPs $(\mathbf{m})$ & DP4D-DGCPs $(\mathbf{m})$ & DPS-DP4D $(\mathbf{m})$ \\
\hline $22-19$ & 137.80 & 0.09 & 0.00 & 0.09 \\
$22-26$ & 196.32 & 0.07 & 0.03 & 0.04 \\
$22-21$ & 154.75 & 0.01 & 0.03 & -0.02 \\
$22-99$ & 145.48 & -0.02 & -0.01 & -0.01 \\
$19-26$ & 80.50 & 0.08 & 0.01 & 0.07 \\
$19-99$ & 188.07 & 0.01 & 0.09 & -0.08 \\
$19-21$ & 98.32 & 0.01 & -0.03 & 0.04 \\
$21-99$ & 113.80 & 0.06 & 0.06 & 0.00 \\
$21-26$ & 71.93 & -0.05 & -0.03 & -0.02 \\
$26-99$ & 185.72 & 0.08 & -0.01 & 0.09 \\
\hline & Mean (m) & 0.03 & 0.01 & 0.02 \\
& r.m.s. $(\mathrm{m})$ & 0.05 & 0.04 & 0.05 \\
\hline
\end{tabular}

The areas were also measured on the 3D models generated by the two software packages. Table 6 lists the measurements and their comparisons with the areas obtained from the DGBT $2 \mathrm{k}$. The third column of Table 6 reports the r.m.s. of each area measured on the DBGT 2k, calculated according to Equation (1). The variation in the r.m.s. depends on the dimensions of the area; a higher surface area corresponds to a higher r.m.s. 
Table 6 shows that the 13\% (in bold type in the Table 6) of the areas measured using Photoscan, are out of tolerance (column 3), while for Pix $4 \mathrm{D}$, the areas that are out of tolerance are $23 \%$. The mean differences are $2.41 \mathrm{~m}^{2}$ and $0.98 \mathrm{~m}^{2}$, respectively, for the DBGT-Photoscan and DBGT-Pix4D comparisons; the r.m.s. are, respectively, $4.62 \mathrm{~m}^{2}$ and $6.05 \mathrm{~m}^{2}$. Figure 14 shows the histograms of the distributions of the area differences between the software and the DBGT 2k, evidencing that the majority of the differences fall into a relatively narrow interval of $\pm 4 \mathrm{~m}^{2}$. It is also important to note the variability of the differences between the areas measured with the two software packages (r.m.s $3.29 \mathrm{~m}^{2}$ ). This is surely due to operator errors in manually selecting the vertices of the areas, in addition to the different parameters used in the processing causing different accuracies in the point clouds.

These results seem to show that a survey with these parameters is not sufficiently accurate for measuring areas for the purpose of urban planning, which often needs an even higher accuracy than a 1:2000 geodatabase. In order to confirm these results, we checked whether the buildings that are out of tolerance were modified or expanded between 2008 (when the DBGT survey was done) and 2016 (time of our survey). This was done by comparing the orthophotos taken in 2008 with those taken in 2016. As shown in the Figure 15a,b, the result was that only the building marked with number 20 and circled in red was expanded.

Table 6. Results of the area measurements.

\begin{tabular}{|c|c|c|c|c|c|}
\hline Building & ADBGT $\left(\mathrm{m}^{2}\right)$ & ADBGT r.m.s $\left(\mathrm{m}^{2}\right)$ & APS-ADBGT $\left(\mathrm{m}^{2}\right)$ & AP4D-ADBGT $\left(\mathrm{m}^{2}\right)$ & PS-P4D $\left(\mathrm{m}^{2}\right)$ \\
\hline 1 & 81.19 & 6.48 & 8.48 & 10.41 & -1.93 \\
\hline 2 & 66.47 & 5.91 & -0.47 & -0.57 & 0.10 \\
\hline 3 & 134.83 & 8.33 & 14.77 & 12.31 & 2.45 \\
\hline 4 & 62.24 & 5.68 & 3.10 & 7.58 & -4.48 \\
\hline 5 & 65.76 & 5.78 & -0.68 & -1.02 & 0.34 \\
\hline 6 & 108.13 & 7.58 & 8.15 & 10.10 & -1.95 \\
\hline 7 & 148.28 & 9.12 & 7.76 & 1.10 & 6.66 \\
\hline 8 & 80.88 & 6.72 & -1.47 & -4.32 & 2.85 \\
\hline 9 & 128.12 & 9.05 & -0.21 & -7.25 & 7.04 \\
\hline 10 & 107.48 & 8.30 & -2.38 & -6.26 & 3.88 \\
\hline 11 & 24.36 & 6.38 & 1.55 & 1.88 & -0.33 \\
\hline 12 & 27.91 & 6.63 & -3.87 & -5.07 & 1.20 \\
\hline 13 & 123.75 & 11.65 & -3.62 & -5.94 & 2.32 \\
\hline 14 & 100.35 & 9.92 & 5.52 & 2.85 & 2.67 \\
\hline 15 & 50.85 & 6.33 & -0.59 & 0.54 & -1.13 \\
\hline 16 & 26.00 & 3.66 & -3.00 & -2.84 & -0.16 \\
\hline 17 & 52.27 & 7.07 & 1.82 & 0.29 & 1.53 \\
\hline 18 & 80.68 & 6.44 & 3.63 & 4.04 & -0.41 \\
\hline 19 & 156.33 & 9.46 & 2.14 & 1.38 & 0.76 \\
\hline 20 & 36.61 & 4.32 & 12.83 & 12.49 & 0.35 \\
\hline 21 & 26.29 & 3.79 & -0.16 & 0.00 & -0.16 \\
\hline 22 & 59.50 & 6.44 & 1.42 & -1.20 & 2.62 \\
\hline 23 & 46.29 & 7.55 & 1.19 & -1.96 & 3.15 \\
\hline 24 & 19.19 & 3.37 & 1.63 & 1.34 & 0.30 \\
\hline 25 & 113.46 & 8.67 & 0.33 & -13.16 & 13.48 \\
\hline 26 & 14.07 & 2.88 & 0.34 & 0.12 & 0.23 \\
\hline 27 & 42.31 & 4.76 & 0.85 & -0.65 & 1.50 \\
\hline 28 & 124.41 & 11.37 & -0.33 & -1.33 & 1.00 \\
\hline 29 & 128.33 & 8.77 & 8.26 & 10.03 & -1.77 \\
\hline \multirow[t]{3}{*}{30} & 76.59 & 6.69 & 5.27 & 4.64 & 0.63 \\
\hline & & Mean $\left(m^{2}\right)$ & 2.41 & 0.98 & 1.42 \\
\hline & & r.m.s. $\left(\mathrm{m}^{2}\right)$ & 4.62 & 6.05 & 3.29 \\
\hline
\end{tabular}


Table 7. Results of the volume measurements.

\begin{tabular}{|c|c|c|c|c|c|}
\hline Building & VDBGT $\left(\mathrm{m}^{3}\right)$ & VDBGT r.m.s $\left(\mathrm{m}^{3}\right)$ & VPS-VDBGT $\left(\mathrm{m}^{3}\right)$ & VPix4D-VDBGT $\left(\mathrm{m}^{3}\right)$ & VPS-VP4D $\left(\mathrm{m}^{3}\right)$ \\
\hline 1 & 252.50 & 45.32 & 19.70 & 26.95 & -7.25 \\
\hline 2 & 221.35 & 41.78 & 18.00 & 18.21 & 0.215 \\
\hline 3 & 544.70 & 75.35 & -56.94 & -57.53 & 0.59 \\
\hline 4 & 261.40 & 39.22 & -4.55 & 13.04 & -17.59 \\
\hline 5 & 236.67 & 38.91 & -19.03 & -14.48 & -4.55 \\
\hline 6 & 698.60 & 72.93 & 23.38 & 33.58 & -10.20 \\
\hline 7 & 612.39 & 83.16 & -0.07 & -3.94 & 3.87 \\
\hline 8 & 208.67 & 44.00 & -13.87 & -5.38 & -8.49 \\
\hline 9 & 442.64 & 71.29 & 12.45 & -5.76 & 18.21 \\
\hline 10 & 493.33 & 73.14 & 5.47 & 11.98 & -6.51 \\
\hline 11 & 61.39 & 20.17 & -16.17 & -13.43 & -2.74 \\
\hline 12 & 61.13 & 20.15 & -12.16 & -14.70 & 2.54 \\
\hline 13 & 450.43 & 73.14 & -49.53 & -41.99 & -7.54 \\
\hline 14 & 333.18 & 60.03 & -14.52 & -25.08 & 10.56 \\
\hline 15 & 142.94 & 31.04 & -13.26 & -12.78 & -0.48 \\
\hline 16 & 73.81 & 16.65 & -10.62 & -8.32 & -2.30 \\
\hline 17 & 122.37 & 30.94 & -5.94 & -5.71 & -0.23 \\
\hline 18 & 429.21 & 52.91 & 15.20 & 13.24 & 1.96 \\
\hline 19 & 478.52 & 83.35 & 39.38 & 51.61 & -12.23 \\
\hline 20 & 90.77 & 21.21 & 42.27 & 39.83 & 2.44 \\
\hline 21 & 135.39 & 23.54 & 5.39 & 7.64 & -2.26 \\
\hline 22 & 163.64 & 34.63 & 23.22 & 24.64 & -1.42 \\
\hline 23 & 87.95 & 31.06 & 16.93 & 10.57 & 6.36 \\
\hline 24 & 62.63 & 14.59 & 1.41 & -3.74 & 5.15 \\
\hline 25 & 623.97 & 69.71 & 37.87 & -3.79 & 41.66 \\
\hline 26 & 43.64 & 11.38 & -2.81 & -3.01 & 0.20 \\
\hline 27 & 119.31 & 25.05 & -5.51 & -12.32 & 6.81 \\
\hline 28 & 334.67 & 69.32 & 2.61 & 2.46 & 0.15 \\
\hline 29 & 562.07 & 77.23 & 74.26 & 70.30 & 3.96 \\
\hline \multirow[t]{3}{*}{30} & 275.72 & 45.24 & 4.83 & 7.87 & -3.04 \\
\hline & & Mean $\left(\mathrm{m}^{3}\right)$ & 13.29 & 12.70 & 0.59 \\
\hline & & r.m.s. $\left(\mathrm{m}^{3}\right)$ & 74.13 & 68.55 & 10.45 \\
\hline
\end{tabular}

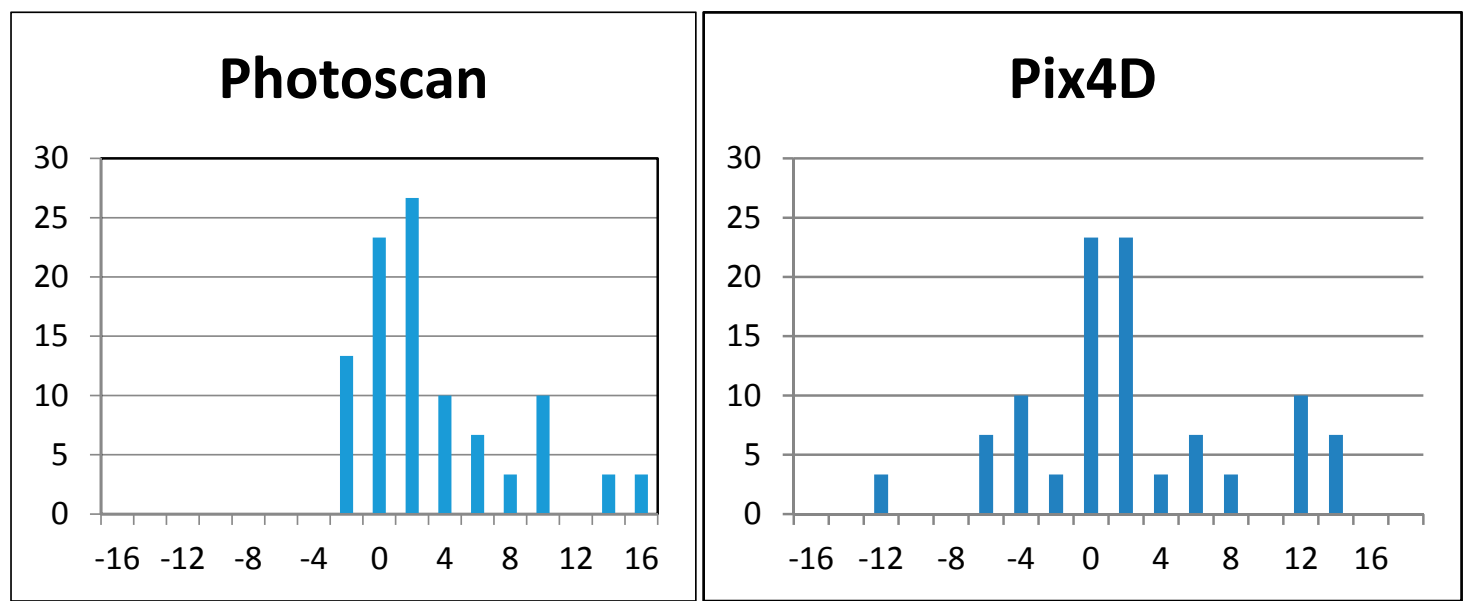

Figure 14. Areas data histogram with frequency (\%) in the y-coordinate and the differences in the $\mathrm{x}$-coordinate. 


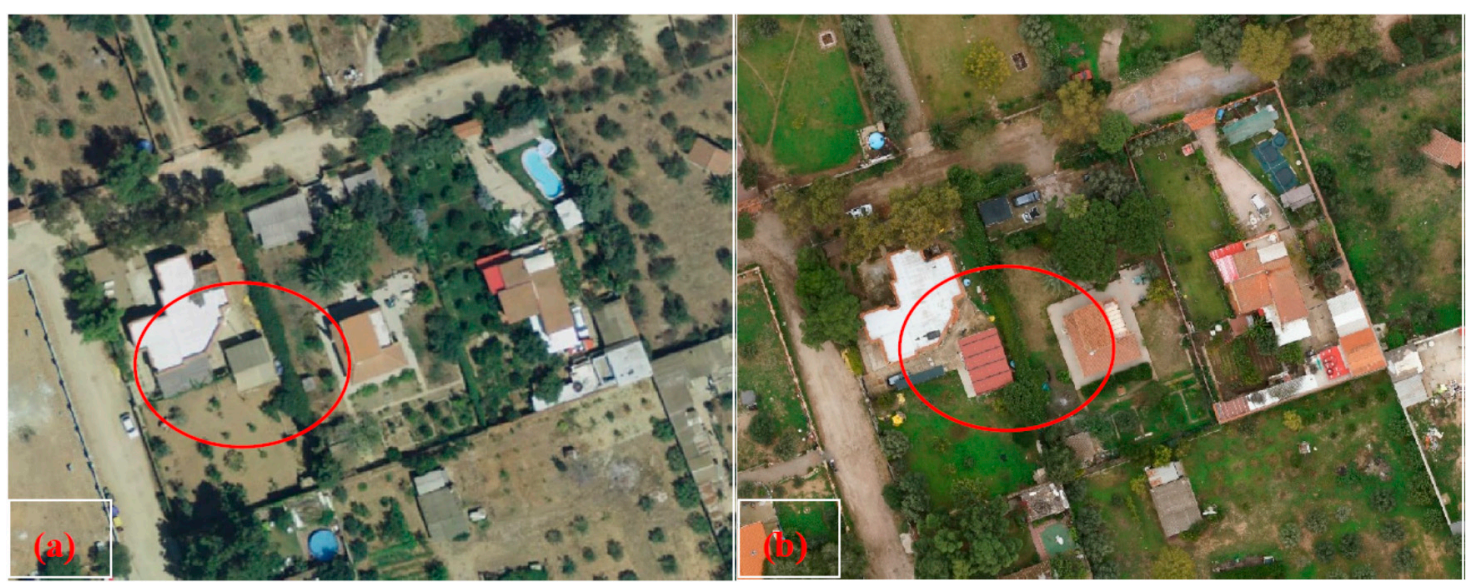

Figure 15. (a) Year 2008 orthophoto; and (b) year 2016 orthophoto.

Looking at the volumes, they were measured both in Photoscan and Pix4D by taking the height from the ground to the eave level, as specified by Italian law for the calculation of the volume of a building. Table 7 and Figure 16 report the results of this measurements.
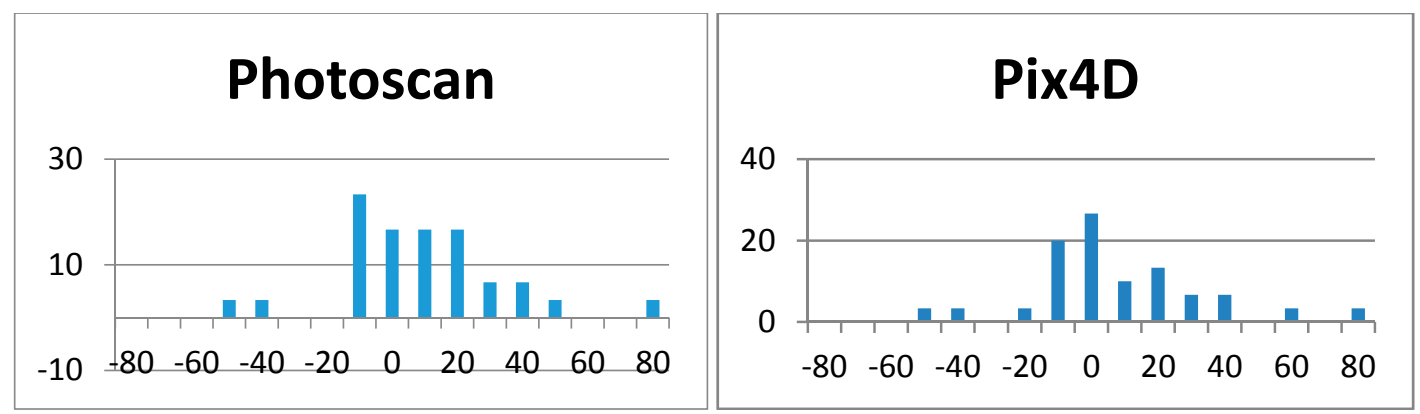

Figure 16. Volume data histograms with frequency (\%) in the y-coordinate and differences in the $\mathrm{x}$-coordinate.

Indeed, the results concerning the measurements of volumes are more encouraging than the ones on the areas. Only one building results in being outside of the tolerance value and it is the number 20 building, which was renovated and expanded after the geodatabase was last updated. All other volumes are within the tolerance for the DBGT $2 \mathrm{k}$.

From Table 7, it can be seen see that the mean differences are $13.29 \mathrm{~m}^{3}$ and $12.70 \mathrm{~m}^{3}$, respectively, for the VPS-VDBGT and VPix4D-VDBGT comparisons, while the r.m.s. are, respectively, $74.13 \mathrm{~m}^{3}$ and $68.55 \mathrm{~m}^{3}$. From the histograms in Figure 16, we can notice that the higher occurrence of differences is in the $\pm 20 \mathrm{~m}^{3}$ range. Additionally, in this case, the difference between the volumes measured by the two software packages (r.m.s $10.45 \mathrm{~m}^{3}$ and mean $0.59 \mathrm{~m}^{3}$ ) is remarkable. Again, these differences are surely due to operator errors in manually selecting the vertices of the areas, in addition to the different parameters used in the processing causing different accuracies in the point clouds.

\subsection{Case Study 2-Oblique Survey}

On the basis of the results of the first case study, we decided to investigate more thoroughly the potential accuracy of UAV system for 3D city modeling in terms of metric measurements on the buildings. This in-depth analysis was necessary to compare the measurements taken in the first case study. In this case, we used the DBGT $2 \mathrm{k}$ which, although accuracy-checked by the local administration that commissioned it, cannot actually be assumed to have the accuracy declared in the metadata. 
Thus, for solving this problem, we planned and executed another flight, this time over a single building, and we validated the results with a terrestrial laser scanner survey done directly by us. The chosen building was an abandoned construction with a regular shape, about $12 \mathrm{~m}$ tall, located in a different area from the one used in the first case study. This second case study was also meant to examine the increase of the accuracy of the 3D model obtained by integrating a nadir with an oblique flight, where the images are taken with a non-vertical camera axis. With this purpose, the nadir flight of the building was integrated with an oblique one and the resulting 3D model was validated by comparing it with the one obtained from the TLS survey.

Nowadays, considering the case of oblique images, the question on the modalities through which flight configuration allows covering the entire building or object is still open [19]. In recent years, several configurations have been tested and evaluated [34]: the Maltese Cross, with a nadir camera and four oblique ones $\left(45^{\circ}\right)$ pointing in the cardinal directions, and the fan configuration, which increases the swath width along the track to cover more area. In our case, the Figure 17 shows that the oblique flight was performed with a $45^{\circ}$ inclination of the optical axis. The UAV system was the same as that used in the first case study.

Table 8 shows the parameters of the flight plan for the nadir and oblique flights. It is important to point out that the nadir flight was realized in fully automatic mode, while the oblique flight was in manual mode. The pilot, in this case, with the help of the remote viewing camera, made the shots attempting to cover the required $80 \%$ overlap. From the pre-processing of the images, however, it has been verified that the overlap of $80 \%$ was guaranteed.

Table 8. Flight parameters.

\begin{tabular}{ccc}
\hline & Flight altitude & $90 \mathrm{~m}$ \\
Nadir flight (called "N") & GSD & $2.20 \mathrm{~cm}$ \\
& Forward overlap & $80 \%$ \\
& Side overlap & $75 \%$ \\
& Number of images & 25 \\
\hline & Flight altitude & $50 \mathrm{~m}$ \\
Oblique flight (called "O") & GSD & $1.2 \mathrm{~cm}$ \\
& Forward overlap & About $80 \%$ \\
& Side overlap & About $80 \%$ \\
& Number of images & 119 \\
& Axis inclination & $45^{\circ}$ \\
\hline
\end{tabular}

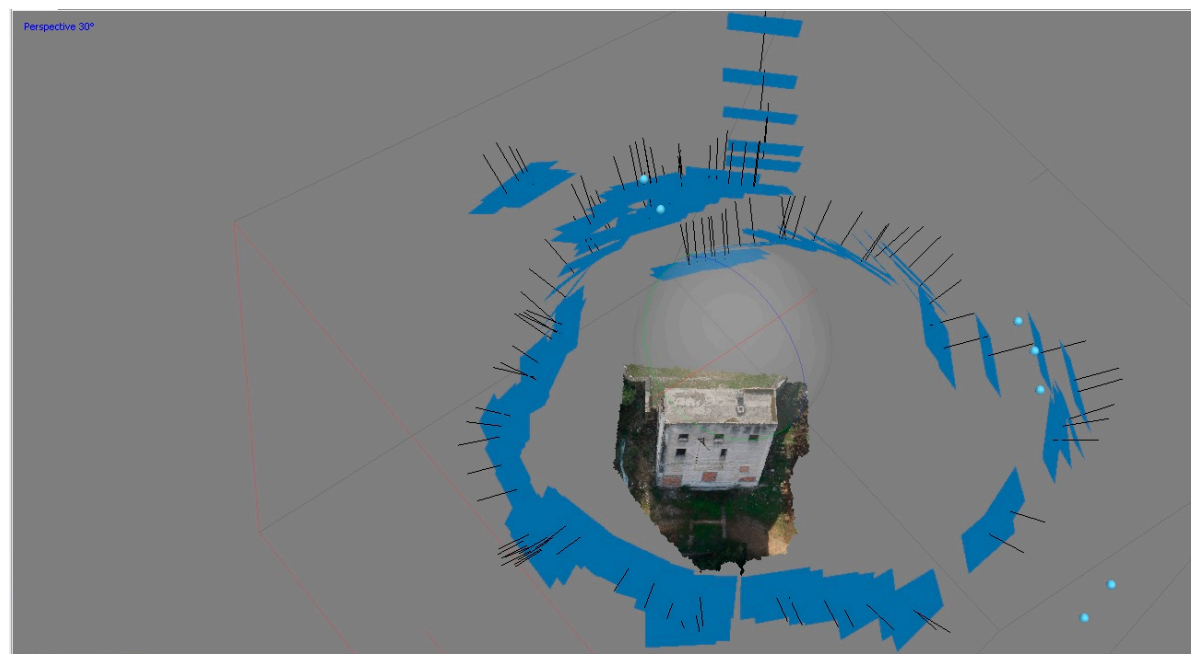

Figure 17. Oblique flight. 
Additionally, in this case the data from the two flights, nadir " $\mathrm{N}$ " and integrated nadir/oblique "N $+\mathrm{O}$ ", were processed using Photoscan and Pix4D with the same parameters of the previous tests. Georeferencing point clouds were made using four GCPs on the terrain and five on the façade (Figure 18b), surveyed in the ETRF2000 datum with the GNSS RTK technique. The r.m.s of the georeferenced image processing have been attested, even in these cases, to a few centimeters.

The TLS survey was done using a Faro Focus 3D laser scanner, with four exterior scans (Figure 18a) with a resolution of one point per $7.67 \mathrm{~mm}$ at $10 \mathrm{~m}[37,38]$.

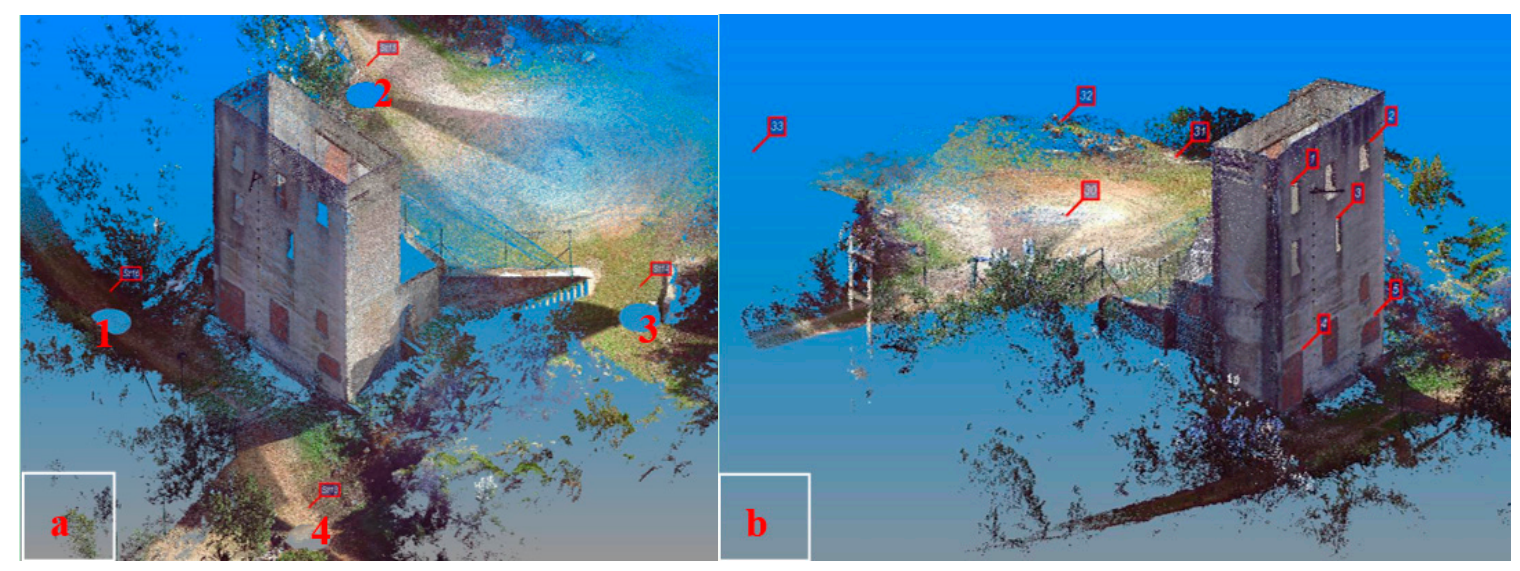

Figure 18. TLS station points (a), and GCPs (b).

The scan data was processed with the JRC Reconstructor software package by Gexcel Ltd. Reconstructor is a software that enables the carrying out of all the processing operations of the point cloud until the 3D model of the structure or building scanned is obtained. The final 3D model is composed by 5,203,483 points and the r.m.s. of the registration is $2 \mathrm{~mm}$. The cloud of TLS points was georeferenced on the same GCPs used for point clouds obtained by UAV flights, with an r.m.s. of $3.5 \mathrm{~cm}$.

Table 9 reports the number of points recorded in the different point clouds representing only the building. It is important to note that, in this case, the different number of points between the results of the processing in Photoscan and Pix $4 \mathrm{D}$ is consistent with the parameters used in processing the dense point clouds. In Photoscan, the Quality parameter was set to "medium", causing a downscaling of the image by a factor of 4 , whereas in Pix $4 \mathrm{D}$, the Image Scale parameter was set to $\frac{1}{2}$, reducing the image size to half.

Table 9. Number of points.

\begin{tabular}{cc}
\hline Flight/Survey and Software & N. of Points in the 3D Model \\
\hline N Flight-Photoscan & 58,740 \\
N Flight-Pix4D & 67,779 \\
N + O Flight-Photoscan & $1,207,609$ \\
N + O Flight-Pix4D & $2,031,823$ \\
TLS Faro Focus 3D & $5,203,483$ \\
\hline
\end{tabular}

The point clouds obtained from the processing were validated in two different ways. The first one consists in taking measurements $\mathrm{L}_{1}, \mathrm{~L}_{2}$, and $\mathrm{H}$ (Figure 19) on the building through the different point clouds; the other one, by calculating the minimal distance between every point of the 3D model obtained from each flight and the 3D model produced by the TLS survey. This calculation used the nearest neighbor algorithm of the CloudCompare program. 


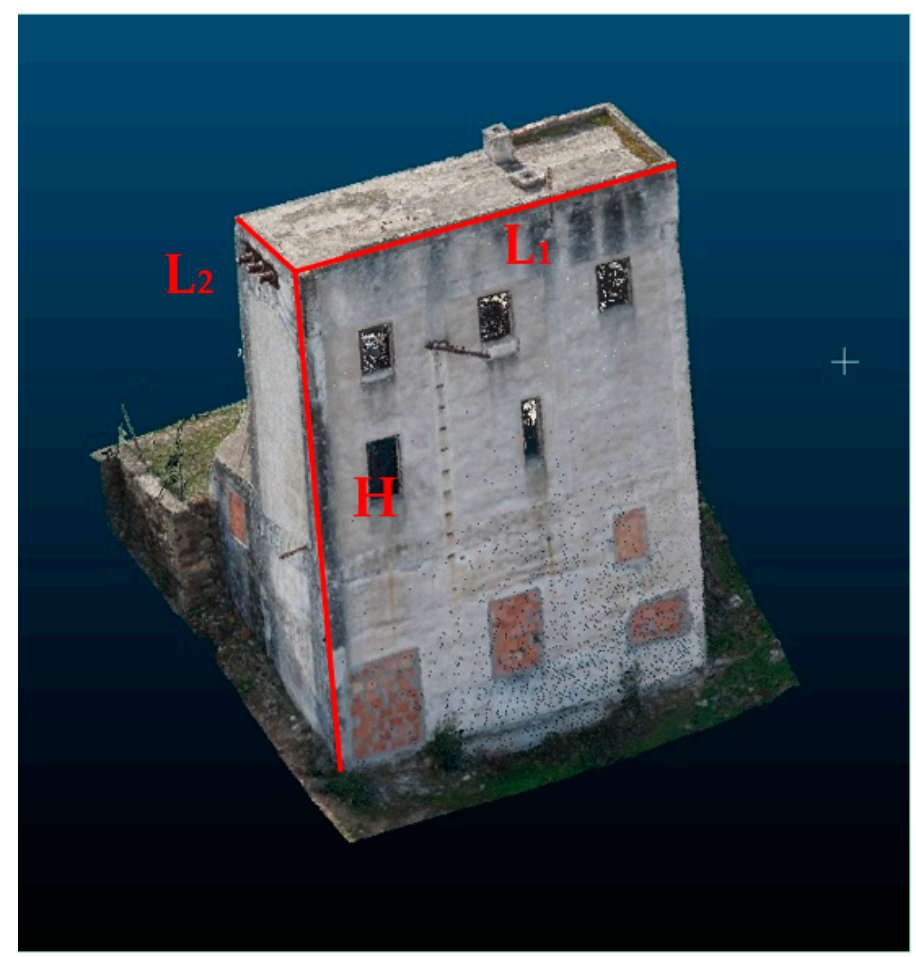

Figure 19. The measurements taken on the building.

Table 10 reports the comparisons between each quantity measured in the Photoscan 3D model and the TLS one.

Table 10. Comparison between the measurements on the Photoscan and TLS.

\begin{tabular}{cccccc}
\hline Measure & TLS & Photoscan $\mathbf{N}$ & Photoscan $\mathbf{N}+\mathbf{O}$ & TLS-Photo $\mathbf{N}$ & TLS-Photo N + O \\
\hline $\mathrm{H}(\mathrm{m})$ & 11.93 & 11.30 & 11.34 & 0.63 & 0.59 \\
$\mathrm{~L}_{1}(\mathrm{~m})$ & 8.72 & 8.22 & 8.53 & 0.50 & 0.19 \\
$\mathrm{~L}_{2}(\mathrm{~m})$ & 3.20 & 2.96 & 3.02 & 0.24 & 0.18 \\
Area $\left(\mathrm{m}^{2}\right)$ & 27.93 & 24.33 & 25.76 & 3.60 & 2.17 \\
Volume $\left(\mathrm{m}^{3}\right)$ & 333.20 & 274.94 & 292.12 & 58.26 & 41.08 \\
\hline
\end{tabular}

Table 11 reports the comparisons between each quantity measured on the Pix4D model and the TLS-generated one.

Table 11. Comparison between the measurements on the Pix4D and TLS point clouds.

\begin{tabular}{cccccc}
\hline Measure & TLS & Pix4D N & Pix4D N + O & TLS-Pix4D N & TLS-Pix4D N + O \\
\hline $\mathrm{H}(\mathrm{m})$ & 11.93 & 11.90 & 11.96 & 0.03 & 0.03 \\
$\mathrm{~L}_{1}(\mathrm{~m})$ & 8.72 & 8.59 & 8.71 & 0.13 & 0.01 \\
$\mathrm{~L}_{2}(\mathrm{~m})$ & 3.20 & 3.01 & 3.19 & 0.19 & 0.01 \\
Area $\left(\mathrm{m}^{2}\right)$ & 27.93 & 25.85 & 27.78 & 2.08 & 0.14 \\
Volume $\left(\mathrm{m}^{3}\right)$ & 333.20 & 307.68 & 332.31 & 25.52 & 0.89 \\
\hline
\end{tabular}

From these tables, it can be seen that, for this building, the nadir flight processed with Pix4D produced rather good results: all the differences are within the tolerances for the DBGT, even if they are not within the TLS tolerances. In other words, the measurements on the point cloud obtained from nadir images in Photoscan are barely within the DBGT 2K tolerances.

Analyzing the results obtained from the point clouds of the $\mathrm{N}+\mathrm{O}$ flight, it is apparent that the integration of the oblique flight has brought a clear improvement to the accuracy of the measurements. 
This increase is more apparent in the dataset processed with Pix $4 \mathrm{D}$ than in the one processed with Photoscan, where the differences with the TLS point cloud are on the order of centimeters for the distances, tens of $\mathrm{cm}^{2}$ for the areas, and tens of $\mathrm{cm}^{3}$ for the volumes. This is surely due to the higher number of points obtained from the Pix4D processing in both configurations, and especially in the $\mathrm{N}+\mathrm{O}$ one [39].

The second validation comported a direct comparison between the point clouds from the different flights and software packages and the single cloud obtained from the TLS survey, through the calculation of the minimal distance between every point. For practical reasons, this comparison did not interest the whole building, but only the northern façade (Figure 20), which did not contain any eaves or obstructions, thus ensuring that the statistical results depend only on the processing and not on the geometry or contour conditions of the examined element [40].

Table 12 reports the number of points of the portion of the point cloud representing the north façade for each configuration.

Table 12. Number of points in the north façade.

\begin{tabular}{cc}
\hline Flight/Survey and Software & No. of Points of the 3D Model \\
\hline Volo N-Photoscan & 8084 \\
Volo N-Pix4D & 14,606 \\
Volo N + O-Photoscan & 187,441 \\
Volo N + O-Pix4D & 224,363 \\
TLS Faro Focus 3D & 515,775 \\
\hline
\end{tabular}

The calculation of the minimal distance between every point of the point clouds obtained from the different flights and software packages and the single cloud obtained from the TLS survey was performed using CloudCompare software, which compares point clouds representing the same object, but acquired at different times and/or with different instruments. CloudCompare also calculates the following statistics: minimal distance, maximal distance, average distance, and standard deviation.

Figure 20 shows the north façade from TLS. Figures 21 and 22 show the north façade from the UAV Nadir flight. Figures 23 and 24 show the north façade from the UAV Nadir + Oblique flight.

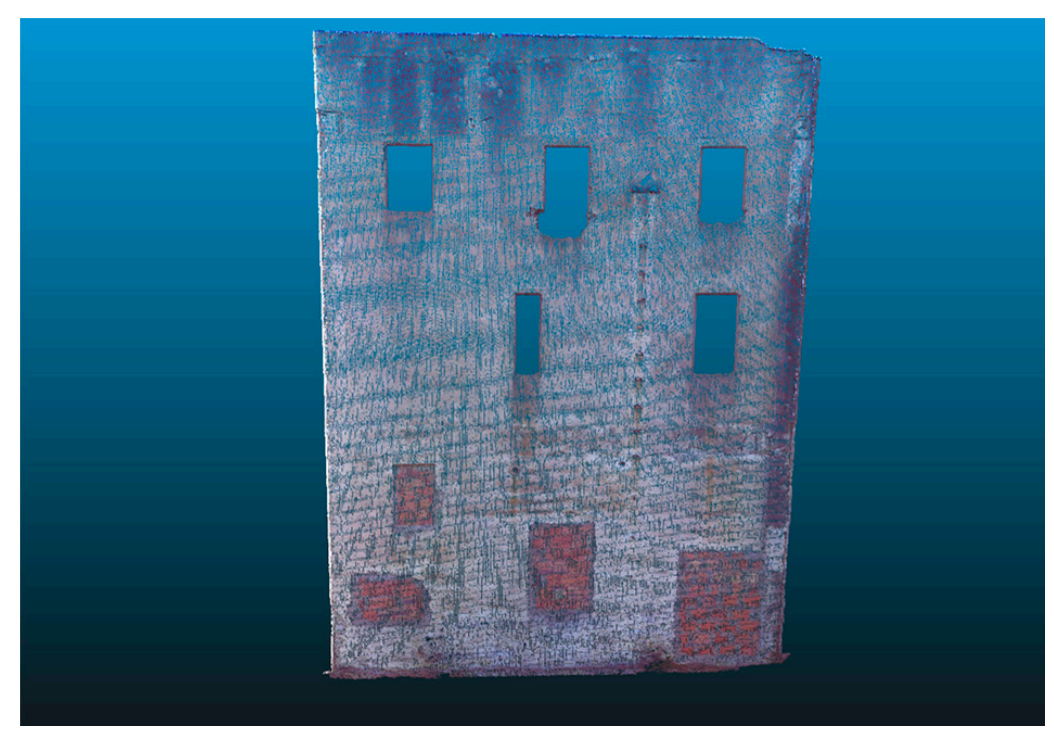

Figure 20. TLS point cloud. 


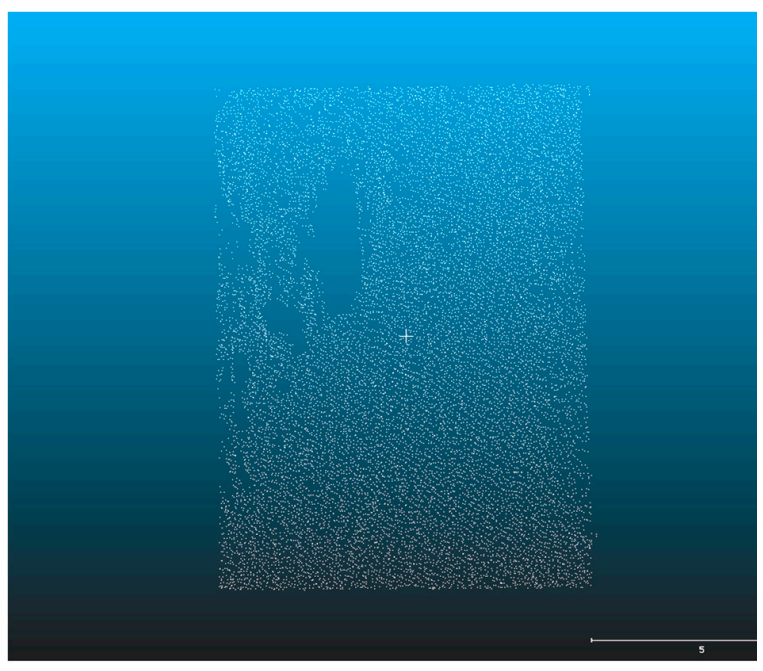

Figure 21. UAV Nadir in Photoscan.

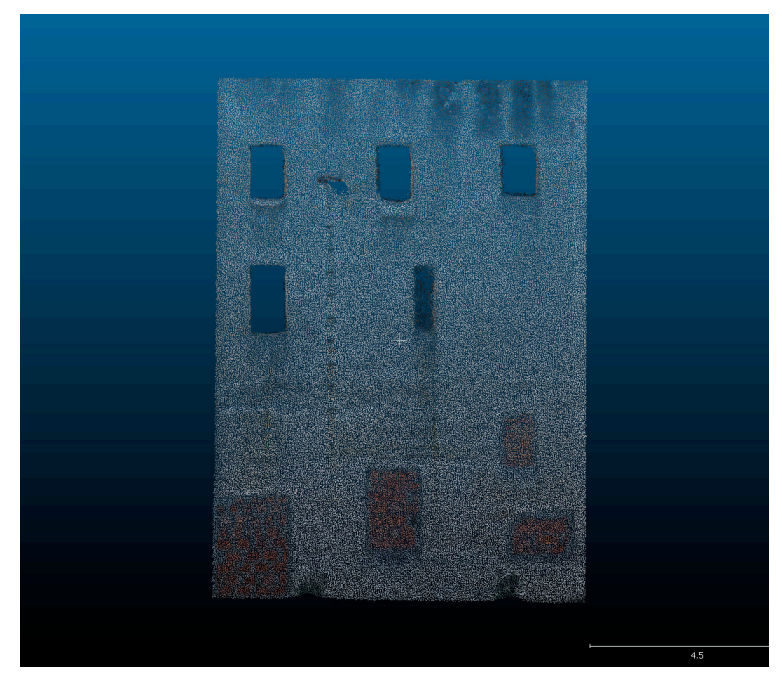

Figure 22. UAV Nadir + Oblique in Photoscan.

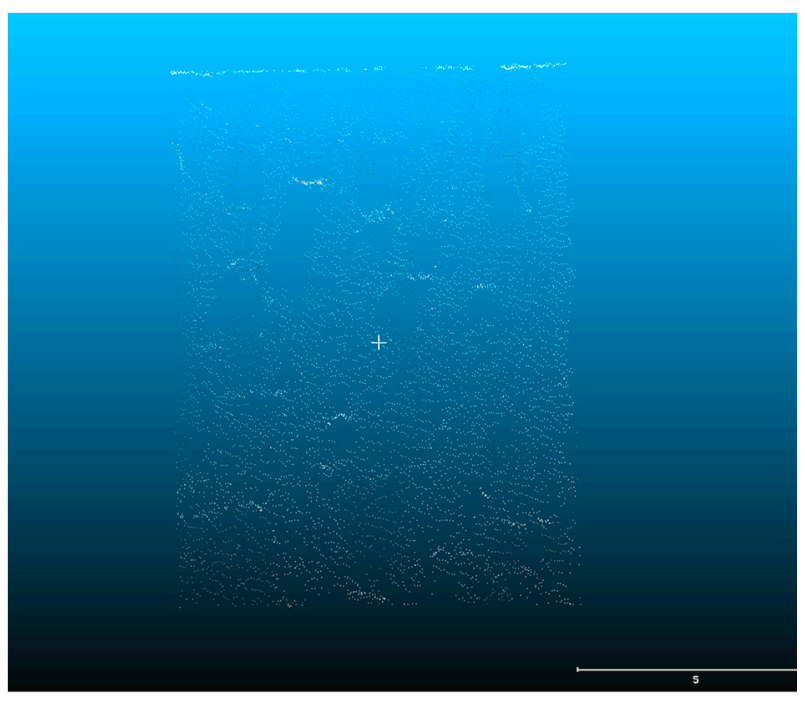

Figure 23. UAV Nadir in Pix4D. 


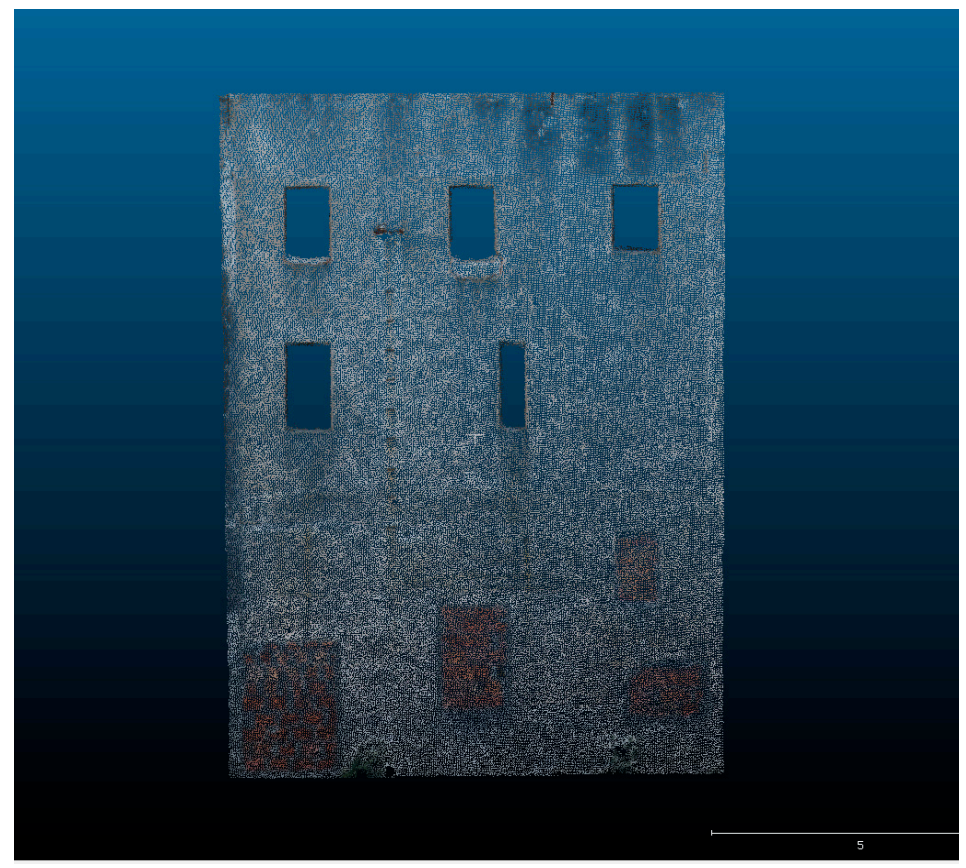

Figure 24. UAV Nadir + Oblique in Pix4D.

Table 13 reports the results of the comparisons between the point clouds obtained in both configurations and with both software packages. Figures 25-28 show the discrepancy maps between the TLS point clouds and the ones obtained from the UAV surveys.

Table 13. Statistical values of the comparisons between the TLS data and the point clouds.

\begin{tabular}{ccccc}
\hline Software & Photoscan N & Pix4D N & Photoscan N + O & Pix4D N + O \\
\hline Min (m) & 0 & 0 & 0 & 0 \\
Max (m) & 0.430 & 0.408 & 0.397 & 0.397 \\
Mean (m) & 0.053 & 0.039 & 0.008 & 0.005 \\
r.m.s. (m) & 0.057 & 0.068 & 0.031 & 0.025 \\
\hline
\end{tabular}
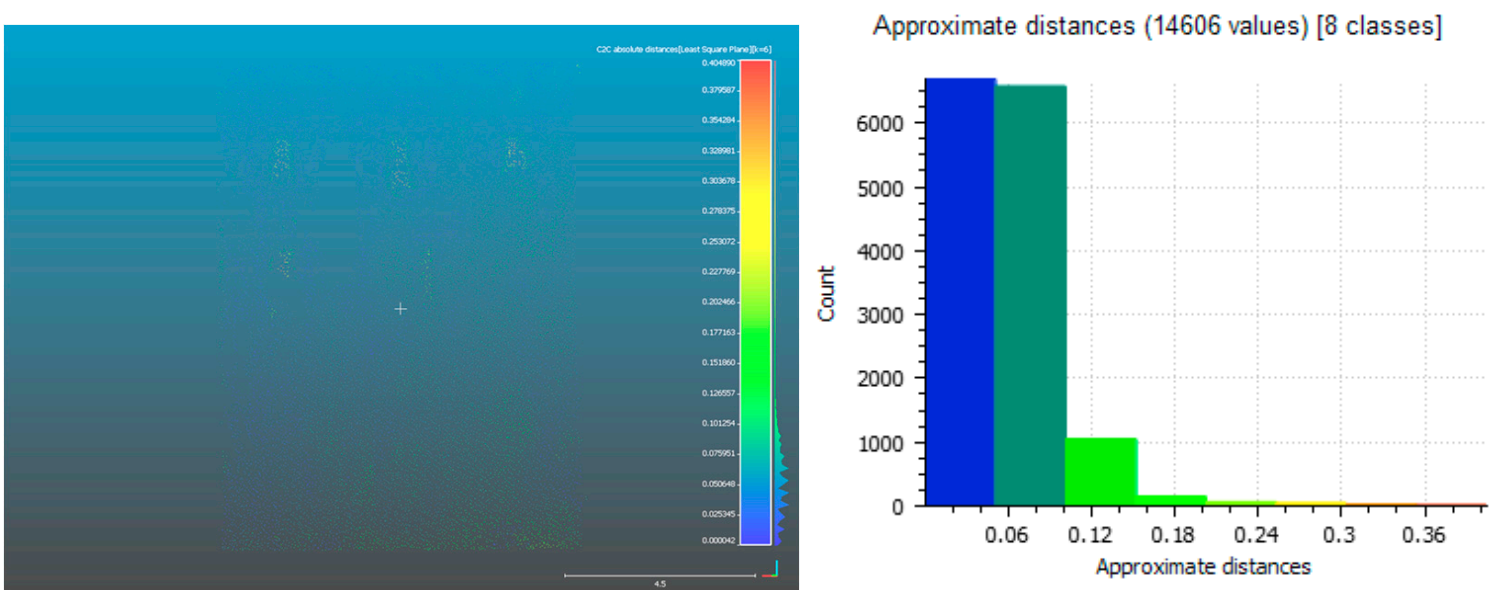

Figure 25. Discrepancy map and histogram between the TLS cloud and UAV Nadir in Photoscan. 

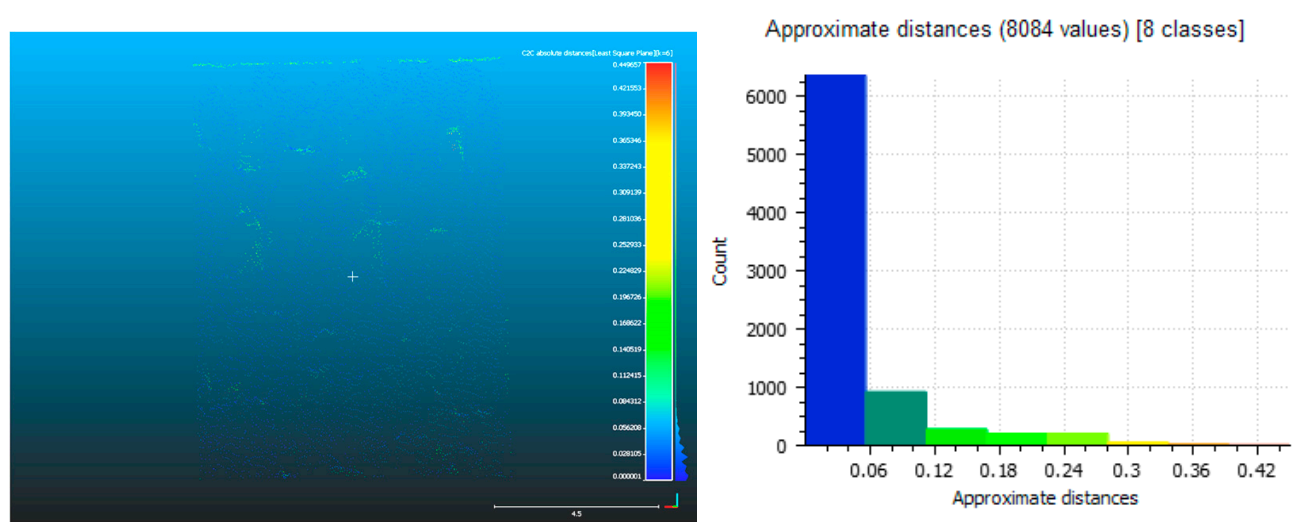

Figure 26. Discrepancy map and histogram between the TLS cloud and UAV Nadir in Pix4D.
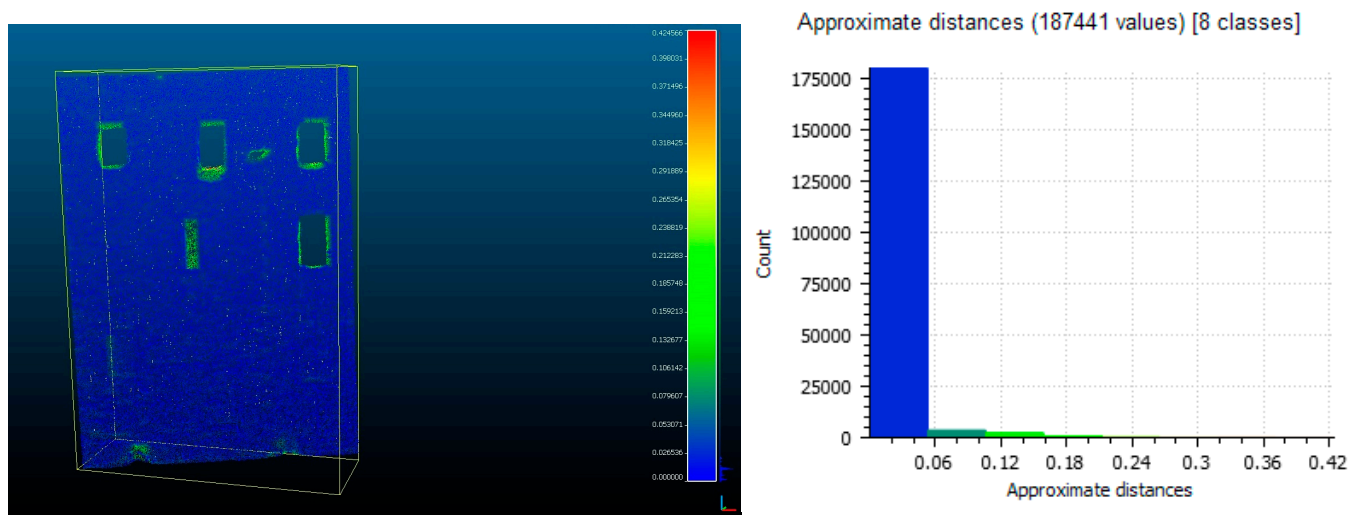

Figure 27. Discrepancy map and histogram between the TLS cloud and UAV Nadir + Oblique in Photoscan.
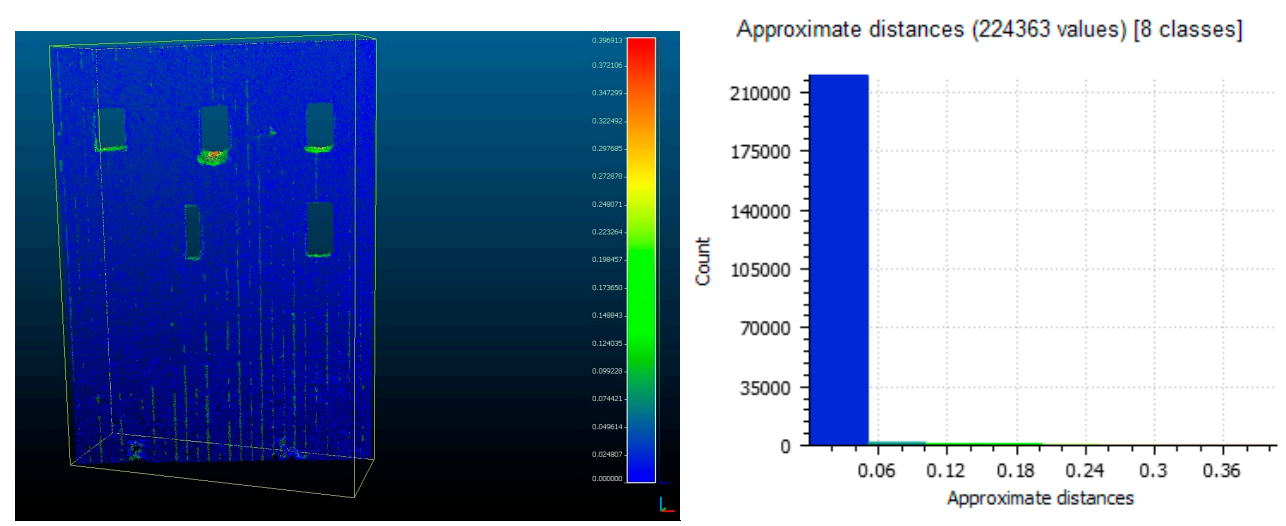

Figure 28. Discrepancy map and histogram between the TLS cloud and UAV Nadir + Oblique in Pix4D.

The comparison between the tables results and between the distance maps, obtained by comparing the point clouds highlights that the integration of the nadir and the oblique flight, increases the number of recorded points considerably, describing the façade in much greater detail. Surely this is an important result for the 3D reconstruction of buildings and on the study of the degradation or deformation of façades. Still, it must be highlighted that the use of oblique imagery increases the flight and processing times.

Regarding the comparison of the distances between the point clouds obtained by processing the UAV imagery and the one obtained from a TLS survey, in this case, the marked improvement in the 
point clouds obtained from the combined nadir/oblique survey with respect to the nadir-only one is apparent. The average distance between the clouds processed with Photoscan and the one obtained from TLS is of $5 \mathrm{~cm}$ for the $\mathrm{N}$ dataset and $0.8 \mathrm{~cm}$ for the $\mathrm{N}+\mathrm{O}$ one. The same improvement can be seen in the clouds processed with Pix $4 \mathrm{D}$, where the average distance changes from about $4 \mathrm{~cm}$ for the $\mathrm{N}$ dataset to $0.5 \mathrm{~cm}$ using the $\mathrm{N}+\mathrm{O}$ dataset.

It is also necessary to make a remark about the maximum distances between the clouds from the UAV surveys and the one from TLS-all the highest values are located near a window placed in the high part of the building. Examining the point clouds in that area, some point fall inside the window and have no direct correspondence with the points of different clouds. If we remove these uncertain parts, the statistics of the point clouds obtained from the $\mathrm{N}+\mathrm{O}$ survey are definitely better.

\section{Conclusions}

The main aim of the presented research was to study the accuracy of some measurements of buildings, such as widths, heights, areas, and volumes, taken of 3D models obtained from processing images acquired from the UAV system. Two case studies were presented: the first one consists of performing a nadir UAV flight on a large built-up area. The second one consists of a UAV flight, both nadir and oblique, on a single building. The first case study did not allow us to fully evaluate the results of the UAV nadir flight, since the only available data for their validation was a 1:2000 scale DBGT with high tolerances ( $0.80 \mathrm{~m}$ tolerance on planimetric coordinates) and with no certainty about the origin of the data (as it is not directly produced by the research group). This first case study, however, allowed us to study and verify the good behavior of the two software packages used for image processing: Photoscan by Agisoft and Pix4D. The results of the two software tools, in fact, are compatible in terms of accuracy, precision, and processing time, as also demonstrated in other research $[19,33]$.

By contrast, the second study case, has allowed us to investigate in more detail the results achieved on the 3D models obtained from nadir and oblique UAV flights. In this case, in fact, the results were compared to those obtained from the 3D model of the building obtained with the TLS survey. From these comparisons, it has been possible to draw several interesting considerations. The results obtained from the 3D model from the oblique flight, for both software packages, were consistent with those obtained with the TLS survey. The increase in accuracy between the nadir images and the oblique images was 90\% for Pix $4 \mathrm{D}$ and an average of 50\% for Photoscan. This increase in difference can be explained by the fact that the number of points in the point clouds built from the Photoscan is lower than that of Pix4D (see Table 9), which did not happen in the first case study of the vast urban area. Considering the results obtained on the analysis of the single north façade, this problem does not appear. In fact, the number of points on the north wall processed with the two-different software (see Table 12) is quite similar. The r.m.s. of the distances between the walls from the UAV are on the order of $6 \mathrm{~cm}$ for the flight processed with Photoscan and $7 \mathrm{~cm}$ for the nadir flight processed with Pix4D. As for the oblique flight, the distances are on the order of $3 \mathrm{~cm}$ for the oblique flight processed with Photoscan and $2 \mathrm{~cm}$ for the one processed with Pix4D. From these results, which prove the increase in accuracy in the reconstruction of the northern façade, we can surely say that the use of oblique images is a great tool for 3D surveying of buildings, especially if they are characterized by limited accessibility and require a fast and low-cost acquisition. Particular attention must be given to the flight planning in order to have images with a good overlay and a similar GSD.

The research will continue, using the oblique flight mode on extended built-up areas, in order to evaluate the potential of the technique and the accuracy of the resulting 3D models of the buildings for the building wide areas. Part of the research will be devoted to the study of the parameters to be used in the different steps of the processing of the point clouds, in order to obtain a more complete picture of the achievable accuracy and processing times.

Acknowledgments: The authors would like to thank the STF-Survey company (http:/ / www.stf-survey.com/site/) of Anda and Giuseppe Furfaro, for their helpfulness during the UAV flights. 
Author Contributions: Giuseppina Vacca conceived and designed the research; Giuseppina Vacca, Alessandro Sacco and Andrea Dessì performed the experiments; Giuseppina Vacca and Alessandro Sacco analyzed the data; Giuseppina Vacca wrote the paper.

Conflicts of Interest: The authors declare no conflict of interest.

\section{References}

1. Ezequiel, C.A.F.; Cua, M.; Libatique, N.C. UAV Aerial Imaging Applications for Post-Disaster Assessment Environmental Management and Infrastructure Development. In Proceedings of the International Conference on Unmanned Aerial Systems, Orlando, FL, USA, 27-30 May 2014; pp. 274-283.

2. Samad, A.M.; Kamarulzaman, N.; Hamdani, M.A.; Mastor, T.A.; Hashim, K.A. The potential of Unmanned Aerial Vehicle (UAV) for civilian and mapping application. In Proceedings of the IEEE 3rd International Conference on System Engineering and Technology (ICSET), Shah Alam, Malaysia, 19-20 August 2013; pp. 313-318.

3. Glade, D. Unmanned Aerial Vehicles: Implications for Military Operations; Air University Maxwell Air Force Base: Montgomery, AL, USA, 2000.

4. Remondino, F.; Barazzetti, L.; Nex, F.; Scaioni, M.; Sarazzi, D. UAV Photogrammetry for mapping and 3D modeling-Current status and future perspectives. In Proceedings of the International Archives of the Photogrammetry, Remote Sensing and Spatial Information Sciences, Zurich, Switzerland, 14-16 September 2011; pp. 25-31.

5. Aicardi, I.; Dabove, P.; Lingua, A.; Piras, M. Integration between TLS and UAV photogrammetry techniques for foresty applications. iForest 2016, 10, 41-47. [CrossRef]

6. Berni, J.A.J.; Zarco-Tejada, P.J.; Suárez, L.; González-Dugo, V.; Fereres, E. Remote sensing of vegetation from UAV platforms using lightweight multispectral and thermal imaging sensors. In Proceedings of the International Archives of Photogrammetry, Remote Sensing and Spatial Information Sciences, Hannover, Germany, 2-5 June 2009.

7. Chiabrando, F.; Nex, F.; Piatti, D.; Rinaudo, F. UAV and RPV systems for photogrammetric surveys in archeological areas: Two tests in the piedmont region (ITALY). J. Archaeol. Sci. 2011, 38, 697-710. [CrossRef]

8. Chiabrando, F.; Lingua, A.; Rinaudo, F.; Spanò, A. Archaeological site monitoring: UAV photogrammetry could be an answer. In Proceedings of the International Archives of Photogrammetry, Remote Sensing and Spatial Information Sciences, Melbourne, Australia, 25 August-1 September 2012.

9. Piras, M.; Taddia, G.; Forno, M.G.; Gattiglio, M.; Aicardi, I.; Dabove, P.; Lo Russo, S.; Lingua, A. Detailed geological mapping in mountain areas using an unmanned aerial vehicle: Application to the Rodoretto Valley, NW Italian Alps. Geomat. Nat. Hazards Risk 2016, 8, 137-149. [CrossRef]

10. Eltner, A.; Mulsow, C.; Maas, H.G. Quantitative measurement of soil erosion from TLS and UAV data. In Proceedings of the ISPRS-International Archives of the Photogrammetry, Remote Sensing and Spatial Information Sciences, Rostock, Germany, 4-6 September 2013; pp. 119-124.

11. Coifman, B.; McCord, M.; Mishalani, R.; Iswalt, M.; Ji, Y. Roadway traffic monitoring from an unmanned aerial vehicle. IEE Proc. Intell. Transp. Syst. 2006, 153, 11-20. [CrossRef]

12. Nex, F.; Remondino, F. UAV for 3D mapping application: A review. Appl. Geomat. 2014, 6, 1-15. [CrossRef]

13. Morgenthal, G.; Hallermann, N. Quality Assessment of Unmanned Aerial Vehicle (UAV) Based Visual Inspection of Structures. Adv. Struct. Eng. 2016, 17, 289-302. [CrossRef]

14. Eschmann, C.; Kuo, C.M.; Kuo, C.H.; Boller, C. Unmanned aircraft systems for remote building inspection and monitoring. In Proceedings of the 6th European Workshop on Structural Health Monitoring, Dresden, Germany, 3-6 July 2012.

15. Kumar, S.K.; Rasheed, A.M.; Kumar, R.K.; Giridharan, M.; Ganesh. Dhaksha, The Unmanned Aircraft System in its new avatar automated aerial inspection of India's tallest tower. In Proceedings of the International Archives of the Photogrammetry, Remote Sensing and Spatial Information Sciences, Rostock, Germany, 4-6 September 2013; pp. 241-246.

16. Xie, F.; Lin, Z.; Gui, D.; Lin, H. Study on construction of 3D building based on UAV images. In Proceedings of the International Archives of Photogrammetry, Remote Sensing and Spatial Information Sciences, Melbourne, Australia, 25 August-1 September 2012; pp. 469-473. 
17. Persad, R.A.; Armenakis, C. Alignment of point cloud DSMs from TLS and UAV platforms. In Proceedings of the International Archives of the Photogrammetry, Remote Sensing and Spatial Information Sciences, Toronto, ON, Canada, 30 August-2 September 2015; pp. 369-373.

18. Cheng, L.; Tong, L.; Li, M.; Liu, Y. Semi-automatic registration of airborne and terrestrial laser scanning data using building corner matching with boundaries as reliability check. Remote Sens. 2013, 5, 6260-6283. [CrossRef]

19. Aicardi, I.; Chiabrando, F.; Grasso, N.; Lingua, A.M.; Noardo, F.; Spanò, A. UAV photogrammetry with oblique images: First analysis on data acquisition and processing. In Proceedings of the International Archives of the Photogrammetry, Remote Sensing and Spatial Information Sciences, Prague, Czech Republic, 12-19 July 2016; pp. 835-842.

20. Koeva, M.; Muneza, M.; Gevaert, C.; Gerke, M.; Nex, F. Using UAVs for map creation and updating. A case study in Rwanda. Surv. Rev. 2016, 1-14. [CrossRef]

21. DGTB. Available online: http:/ $/$ www.sardegnageoportale.it $/$ index.php? $x s l=2425 \& s=325563 \& v=2 \& c=$ $14414 \& \mathrm{t}=1 \& \mathrm{tb}=14401$ (accessed on 15 February 2017).

22. Agisoft Software. Available online: http://www.agisoft.com/ (accessed on 10 January 2017).

23. Pix4D Professional Drone Mapping and Photogrammetry Software. Available online: https://pix4d.com/ (accessed on 10 January 2017).

24. SmartNet Italy. Available online: http:/ / it.smartnet-eu.com/ (accessed on 13 November 2016).

25. Barbarella, M. Digital technology and geodetic infrastructures in Italian cartography. Città e Storia 2014, 9, 91-110.

26. Biagi, L. I Fondamentali del GPS; Geomatics Workbooks; mediaGEO soc. coop: Roma, Italy, 2009; Volume 8, pp. 157-171, ISSN 1591-092X.

27. Szeliski, R. Computer Vision: Algorithms and Applications; Springer: Berlin, Germany, 2010.

28. Westoby, M.J.; Brasington, J.; Glasser, N.F.; Hambrey, M.J.; Reynolds, J.M. 'Structure-from-Motion' photogrammetry: A low-cost, effective tool for geoscience applications. Geomorphology 2012, 179, 300-314. [CrossRef]

29. Photoscan Manual. Available online: http://www.agisoft.com/pdf/photoscan-pro_1_1_en.pdf (accessed on 23 April 2017).

30. Pix4D Manual. Available online: https://support.pix4d.com/hc/en-us/sections/200591059-Manual\#gsc. tab=0 (accessed on 23 March 2017).

31. Disciplinare Tecnico Database Geotopografico Della Regione Sardegna in Scala 1:2000. Available online: http: / / www.sardegnageoportale.it $/$ index.php?xsl=2425\&s=325563\&v=2\&c=14414\&t=1\&tb=14401 (accessed on 23 January 2017).

32. CAM2. Available online: http:/ / www.faro.com/ (accessed on 10 January 2017).

33. Gexcel Geomatics\&Excellence. Available online: http://www.gexcel.it/it/software/jrc-3d-reconstructor (accessed on 30 January 2017).

34. Cloud Compare 3D Point Cloud and Mesh Processing Software. Available online: http:/ /www.cloudcompare.org (accessed on 30 March 2017).

35. Rossi, P.; Mancini, F.; Dubbini, M.; Mazzone, F.; Capra, A. Combining nadir and oblique UAV imagery to reconstruct quarry topography: Methodology and feasibility analysis. Eur. J. Remote Sens. 2017, 50, 211-221. [CrossRef]

36. Petrie, G. Systematic Oblique Aerial Photography using Multiple Digital Frame Cameras. Photogramm. Eng. Remote Sens. 2009, 75, 102-107.

37. Vacca, G.; Mistretta, F.; Stochino, F.; Dessi, A. Terrestrial laser scanner for monitoring the deformations and the damages of buildings. In Proceedings of the International Archives of Photogrammetry, Remote Sensing and Spatial Information Sciences, Prague, Czech Republic, 12-19 July 2016; pp. 453-460.

38. Deidda, M.; Vacca, G. Tecniche di rilievo Laser Scanner a supporto del progetto di restauro conservativo dei beni culturali. L'esempio del Castello di Siviller e del campanile di Mores. Boll. SIFET 2012, 4, 23-39.

39. Remondino, F.; Nex, F.; Menna, F.; Nocerino, E.; Spra, M.G. State of the art in High Density image matching. Photogramm. Rec. 2014, 29, 144-166. [CrossRef]

40. Vacca, G.; Deidda, M.; Dessi, A.; Marras, M. Laser scanner survey to cultural heritage conservation and restoration. In Proceedings of the International Archives of Photogrammetry, Remote Sensing and Spatial Information Sciences, Melbourne, Australia, 25 August-1 September 2012; pp. 589-594.

(C) 2017 by the authors. Licensee MDPI, Basel, Switzerland. This article is an open access article distributed under the terms and conditions of the Creative Commons Attribution (CC BY) license (http://creativecommons.org/licenses/by/4.0/). 